\title{
A Comparative Morphological Study of the Genus Juniperus L. (Cupressaceae) in North of Iraq
}

\author{
Haees Sayel Jarjes Al- Jowary ${ }^{*}$, Aseel Aamer Aanad Al-Sharefy ${ }^{2}$ \\ ${ }^{1,2}$ Department of Foerstry Science, College of Agriculture and Forestry, University of Mosul, Mosul, Iraq \\ E-mail: 1" $\underline{\text { haees_Sayel@uomosul.edu.iq. }{ }^{2} \text { Aseel Alshorafy1990@gmail.com }}$
}

(Received May 15, 2020; Accepted July 26, 2020; Available online December 01, 2020)

DOI: 10.33899/edusj.2020.127106.1073, @ 2020, College of Education for Pure Science, University of Mosul.

This is an open access article under the CC BY 4.0 license (http://creativecommons.org/licenses/by/4.0/).

\begin{abstract}
:
A new species Registration of juniper is Juniperus macrocarpa, permissions not previously registered in Flora of Iraq that were composed (Guest researchers and Ali al-Rawi,1966) so only two species of Juniperus oxycedrus and Juniperus polycarpos were registered at the time. The research included a classification of the species Juniperus which belong to the Cupressaceae family that grown a wild plants in north of Iraq, using the morphological characteristics of (3) species of veins mentioned in (7) sites distributed in provinces of (FNI,MAM and MSU )Nineveh, Dohuk and Sulaymaniyah.

The study includes the characteristics of stems, branches, bark, needle leaves, male and female cones, seeds and flower buds, as well as examining the overcoming of appearance between species and individuals of the same species in the studied sites, and sometimes the species have clear variations among them and the individuals of the same species did not show marked changes, and it became clear that the studied morphological characteristics have taxonomic. Significant in the diagnosis and isolation of species from each other, and the study was reinforced with photographs, shapes and illustrations, as well as the study showed that sexual characteristics (male and female cones and flower buds) are more proven compared to the rest of the characters, and It has a significant and taxonomic role in diagnosing the studied species into groups, so the needle leaves showed clear variations, which makes them the task of classifying them either in their quantitative or qualitative characteristics. The shell of the stem between the species varied markedly and is in the color characteristic, while the most effective charaters in the diagnosis and distinguishing the species were the characteristics of the fruit cones. The cone of seeds (fruits), as the species Juniperus macrocarpa (syno: J. oxycedrus subsp. macrocarpa) prevailed in the size of its large fruits and their dimensions compared to the other two species., as the characteristics of the fruits owning the lobes and the color of the fruits, and the seeds of the species gave clear variations, whether in their quantitative or qualitative characteristics, which also contributed effectively in diagnosing the studied juniper species. Male cones and flower buds had a great taxonomic value.
\end{abstract}

Keywords: Juniperus L., Morphological Study. Cupressaceae Iraq. 


\title{
دراسة مظهرية مقارنة لجنس العرعر Juniperus ضمن العائلة (Cupressaceae) في شمال العرق
}

\author{
هايس صايل جرجيس الجواري1"، اسيل عامر عناد الشريفي2 \\ 2، قسم علوم الغابات، كلية الزراعة والغابات، جامعة الموصل، الموصل، العراق
}

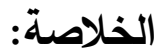

تسجيل نوع جديد من العرعر وهو النوع Juniperus macrocarpa ، إذ لم يسبق أن تم تسجيله في الموسوعة النباتية العراقية التي

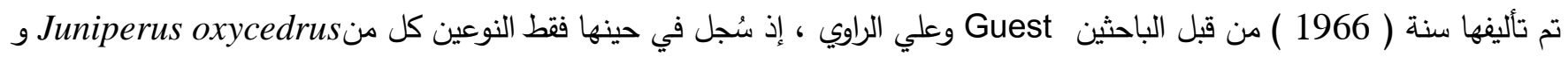
Cupressaceae Juniperus polycarpos ، وقد تضمن البحث دراسة مظهرية لأنواع جنس العرعر التابع للعائلة السروين النامية بصورة برية في شمال العراق لـ ( 3 ) أنواع من العرعر في ( 7 ) مواقع تتوزع في مقاطعات نينوى ودهوك والسليمانية. شملت هذه الدراسة صفات السيقان والأفرع والقلف والأوراق الإبرية والمخاريط الذكرية والأنثوية والبذور والبراعم الزهرية ، كما درست

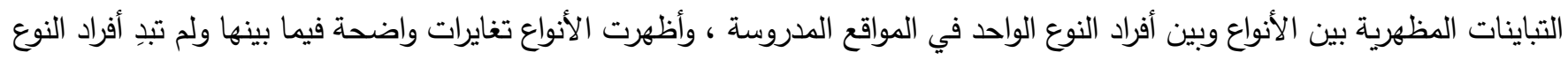
الواحد تغايرات ملحوظة ، واتضح أن للصفات المظهرية المدروسة أهمية تصنيفية كبيرة في تثخيص وعزل الأنواع عن بعضها ، وعُززت الدراسة باللوحات والأشكال التوضيحية ، كذلك بينت الدراسة أن الصفات الجنسية ( المخاريط الذكرية والأنثوية والبراعم الزهرية ) هي الأكثر ثبوتاً مقارنة ببقية الصفات ، وكان لها أهمية تصنيفية كبيرة وبارزة في عزل ألانواع المدروسة إلى مجاميع ، إذ أبدت ألاوراق تغايرات

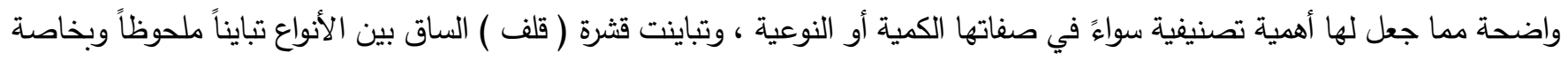
قي صفة اللون ، أما الصفات الأبرز وذات القيمة التصنيفية الأكبر التي ساهمت بشكل فعال في تمييز الأنواع فكانت صفات المخاريط

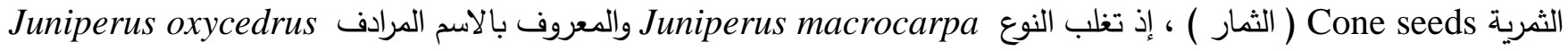
subsp. macrocarpa دوراً بارزاً في فصل الأنواع ، كصفة إمتلاك الثمار للفصوص ولون الثمار التي كان لها قيمة تصنيفية بالغة ، كما أعطت بذور الأنواع تباينات واضحة سواءً في صفاتها الكمية او النوعية والتي ساهمت هي الآخرى بشكل فعال في عملية التثخيص. وكان للمخاريط الذكرية

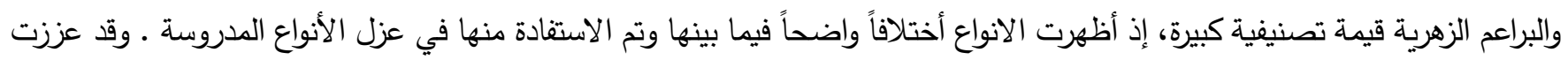
الدراسة بالصور •

الكلمات المفتاحية: العرعر ، دراسة مظهرية . Cupressaceae). ، Juniperus L) ، العرلق.

\section{Introduction المقدمة}

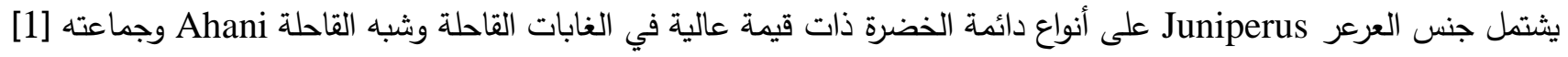

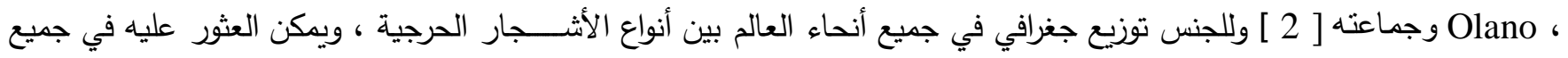

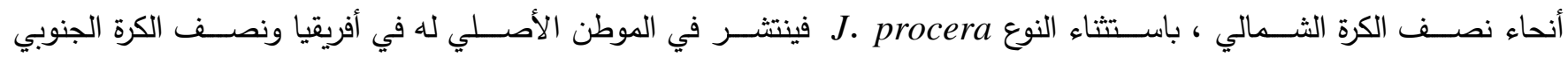
[ Tylkowski 3 ] ، كما ينتشر جنس العرعر في غرب الولايات المتحدة الأمريكية وفي شمال المكسيك وفي وسط وجنوب غرب أسيا. 


\section{Journal of Education and Science (ISSN 1812-125X), Vol: 29, No: 4, 2020 (154-176)}

ويوجد العرعر أيضـا بصورة رئيسية في Eursian مع نوع واحد Adams [4 Farjon J. drupacea وجماعته [5] ، ويتواجد النوع Juniperus polycarpos والعراق وشبه الجزيرة العربية. واهم أنواع العرعر المنتشرة في منطقة البحر الأبيض المتوسط بحسب Daoud [ 6 [ ] . العرعر الثائع .Juniperus communis L. يستخرج منه الزيت الذي يدخل في صناعة المشروبات الروحية. العرعر الشربين يستخرج منه زيت يدعى زيت الكاد. Juniperus oxycedrus L.

السذاب.Juniperus excels Bieb

Juniperus virginiana L.العرعر الفرجيني او الشرقي أما النوع المنتشر في العرا ق بكثرة فهو Juniperus oxycedrus .

يعرف علم التصنيف النباتي Plant taxonomy بأنه العلم الذي يقوم بدراسة النباتات ويشخصها ويسيها ويصنفها، ويرتبط هذا العلم ارتباطاً وثيقاً بعلم التقسيم النباتي Plant systematic، ولا توجد حدود فاصلة بين الاثنين في الممارسة العملية ، بيد أن العلاقة الدقيقة

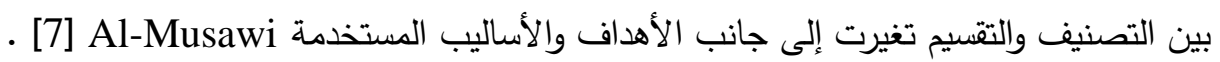

تعد ألانواع التابعة لجنس العرعر Juniperus من أنواع الأشجار ذات القيمة الاقتصادية الكبيرة والواعدة طبياً وبيئياً ( إذ تعدّ من الأشجار الجذابة الظليلة ذات الرائحة المنعشة لما تحتويه من كميات وفيرة من الزيوت الطيارة. ولقد ثبت أن بعض أنواع العرعر هي من الأشجار المعمّرة ، إذ اكتثف في أمريكا أشجاراً تبلغ من العمر مئات السنين. ولبعض أنواعه تاريخ عريق في علاقته مع الإنسان يعود إلى آلاف السنين فقد ذكر العرعر في وصفات فرعونية في بردية "هيرست" و"ايبرز" وصنعوا منه عشرات الأدوية، مرورا بابن سينا وابن البيطار وداود الأنطاكي وغيرهم. وتطورت هذه العلاقة عبر التاريخ لتغدو هذه الثجرة ثروة اقتصادية كبيرة في بعض دول العالم التي قدرتها حق تقدير واستثرتها خير استثمار في المجالات التطبيقية الطبيّة والغذائية والبيئية Adams [8] ) ، وبالرّغم من الاهتمام العالمي الكبير بجنس العرعر بقيت الأنواع المحلية مهملة، مجهولة القيمة، تتعرض لمختلف الإجهادات البيئية، وقد سعينا جاهدين من خلال بحثنا هذا

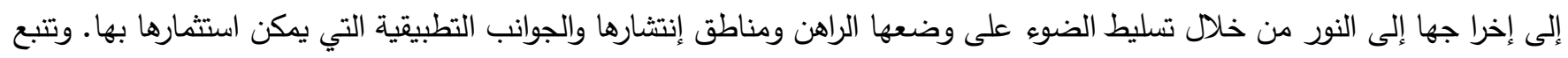
أهمية البحث من كونه يجري للمرة الأولى في العراق حيث دفعتا ندرة المراجع والأبحاث المحلية المهتمة بهذه الأنواع النامية بصورة طبيعية في العراق إلى درا ستها والتوجيه للإهتمام بها بغية الحفاظ عليها كأحد المصادر الوراثية الهامة وإبراز أهميتها التصنيفية ـ كما تبرز أهمية البحث في تحديد أنواع جنس العرعر المنتشرة طبيعياً في شمال العراق، وتحديد مناطق إنتشارها الجغرافي فيه. فضلا عن دراسة الصفات

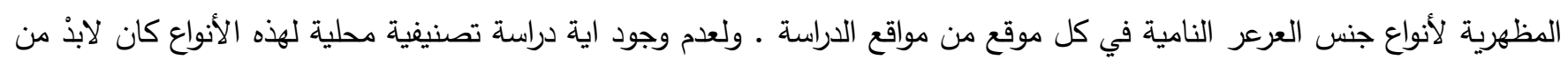

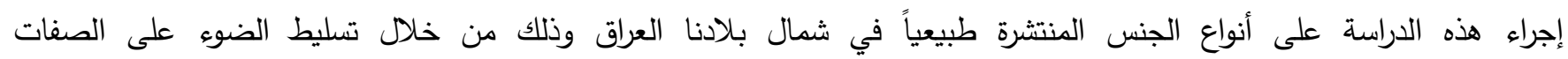

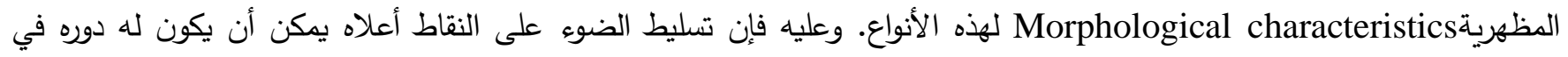
المحافظة على هذه الأنواع المهددة بالإنقراض والتعريف بها على نحو علمي، مما سيخدم أهداف حماية التنوع الحيوي والتنمية المستدامة 
اعتمدت الدراســـة الحالية على العينات الطرية والمجفقة والتي جمعت اثثاء القيام بالعديد من الزيارات الحقلية ( المســوحات الميدانية ) التي اجريت في عامي 2019 و 2020 م والتي شملت ( 7 ) مواقع مختلفة من شمال العراق في مقاطعات ( نينوى ودهوك والسليمانية ) كما هو موضح في الجدول ( 1 ) وخاصة في المناطق الجبلية التي ينتشر فيها جنس العرعر بشكل طبيعي . Juniperus L. L. الجدول (1) مواقع الدراسة ونسبة انتشار كل نوع من أنواع جنس العرعر

\begin{tabular}{|c|c|c|c|c|c|c|c|c|c|}
\hline \multirow[b]{2}{*}{$\begin{array}{c}\text { الانتشار } \\
\text { \% }\end{array}$} & \multirow{2}{*}{ 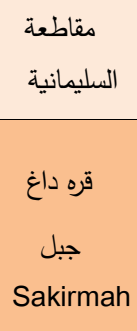 } & \multicolumn{3}{|c|}{ مقاطعة دهوك } & \multicolumn{3}{|c|}{ مقاطعة نينوى } & \multirow[b]{2}{*}{ Speciesالانواع } & \multirow[b]{2}{*}{ ت } \\
\hline & & بيركا & $\begin{array}{c}\text { سواره توكاحية } \\
\text { سيرسنكaratuka } \\
\text { سياحية }\end{array}$ & $\begin{array}{l}\text { كورت } \\
\text { كفانات } \\
\text { Zawita }\end{array}$ & بكرمان عترة (3) جبل & جبل سري & $\begin{array}{l}\text { عقرة) } \\
\text { Akre }\end{array}$ & & \\
\hline $\begin{array}{r}85.7 \\
\%\end{array}$ & & + & + & + & + & + & + & Juniperus oxycedrus & 1 \\
\hline $\begin{array}{c}28.57 \\
\%\end{array}$ & & + & & & + & & & Juniperus macrocarpa & 2 \\
\hline $\begin{array}{r}14.2 \\
\%\end{array}$ & + & & & & & & & Juniperus polycarpos & 3 \\
\hline
\end{tabular}

وبسبب تباين مواقع الدراسة بارتفاعاتها عن سطح البحر وكذلك تباينها بخطوط الطول والعرض فأن الجدول ( 2 ) يوضح مواقع الدراسة وارتفاعاها عن سطح وخطوط الطول والعرض لكل موقع كما هو موضح

GPS الجدول(2) مواقع الدراسة وارتفاعها عن سطح البحر وخطوط العرض والطول بأستخدام جهاز 
Journal of Education and Science (ISSN 1812-125X), Vol: 29, No: 4, 2020 (154-176)

\begin{tabular}{|c|c|c|c|}
\hline خطوط العزض & خطوط الطول & $\begin{array}{c}\text { الارتفاع عن مستوى سطح (م) } \\
\text { (البحر }\end{array}$ & الموقع \\
\hline 36.0743626 & 44.025296 & 1031 & عقرة(1) نينوى \\
\hline 36.752823 & 44.01778 & $1200-1142$ & عقرة(2) نينوى \\
\hline 36.832107 & 43.692974 & 777 & عقرة(3) نينوى \\
\hline 36.924003 & 43.148377 & 900 & زاويته دهوك \\
\hline 37.005280 & 43.218864 & 1196.50 & سواره توكآ دهوك \\
\hline 36.923992 & 43.148376 & 926.4 & اتروش دهوك \\
\hline 35.223294 & 45.403877 & 1413 & قره داغ السليمانية \\
\hline
\end{tabular}

واستخدم جهاز الهاكا Haga Altimeter وطبق القانون الاتي لحساب ارتفاع الاشجار: ع = القراءة السفلى-القراءة العليا X أما العينات التي جمعت خلا الجولات الحقلية فهي ( الاغصان، الاوراق، المخاريط الذكرية، البراعم الزهرية ، المخاريط الانثوية(الثمار)

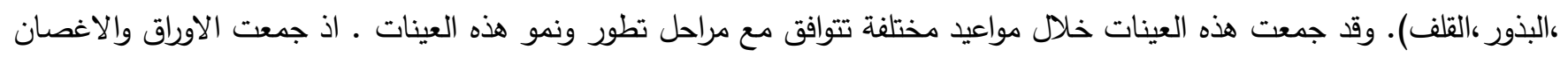
في شهر( تموز) ـ أما المخاريط فجمعت في ( نهاية شهر نيسان وبداية شهر أيار). حسب الانواع وفترة تقتح البراعم الزهرية للمخاريط الذكرية. كما تمت دراسة الصفات الكمية والنوعية للأوراق والمخاريط والثمار والبذور والاغصان وكما هو موضح في الجداول ( 3 ، 4 ، 4 ،

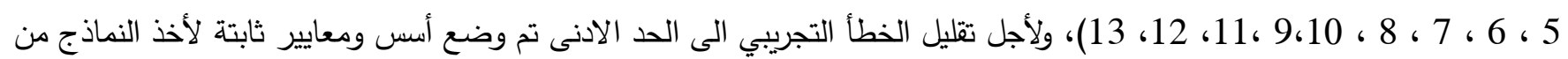
الأوراق واجراء القياسات المباشرة حيث اعتمد على اتجاه واحد لكل شجرة وهو اتجاه الثمال من وسط التاج لأخذ العينات Blue و و [9]. وتم مراعاة اخذ الأوراق السليمة ومن (3) افرع لكل شجرة وبواقع (10) اوراق لكل فرع وبذلك بلغ عدد الأوراق (30) ورقة لكل شجرة

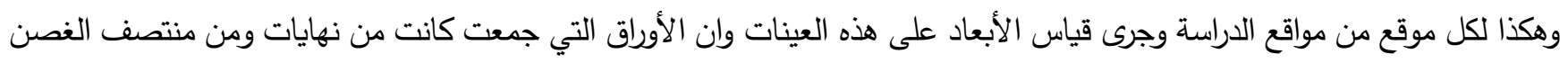

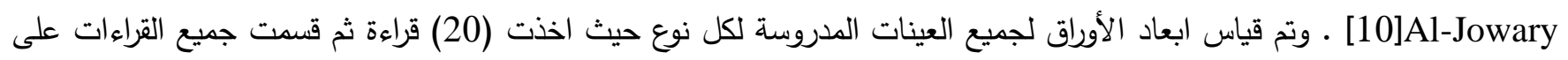

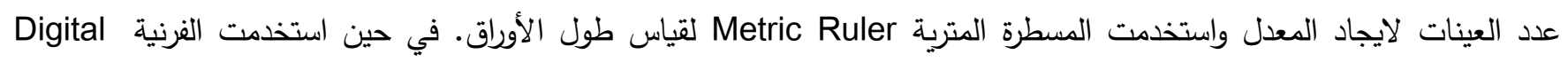
Vernier Caliper

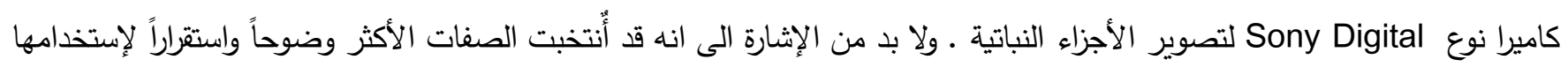

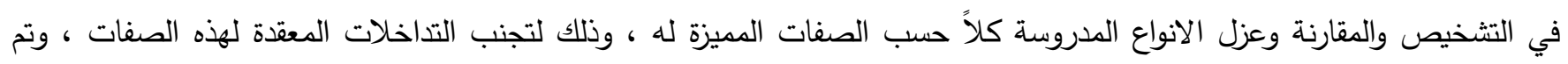

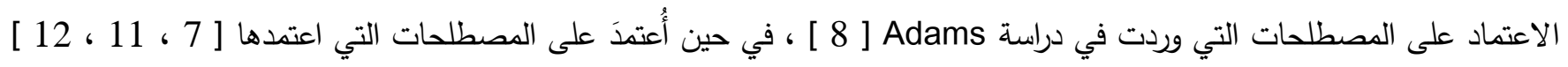
في تعريب المصطلحات.

النتائج والمناقشة 


\section{Journal of Education and Science (ISSN 1812-125X), Vol: 29, No: 4, 2020 (154-176)}

\section{: Duration And Habit الديمومة وطبيعة الإنواع}

أوضحت نتائج الدراسة أن أنواع جنس العرعر Juniperus النامية برياً في شمال العراق قيد الدراسة ذات طبيعة شجرية وشجيرية

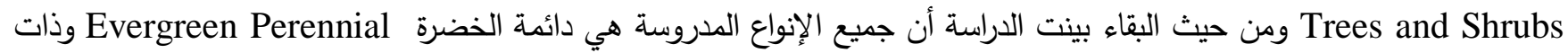
قوام خشبي كما هو موضح في الثكل (1)، وبذلك يتضح أن صفة الديمومة وطبيعة الإنواع كانت ذات قيمة تصنيفية ، إذ تم عزل وتشخيص الإنواع ذات الطبيعة الثجيرية Shrubs عن الإنواع ذات الطبيعة الثجرية Trees ، إذ تم عزل النوع J. oxycedrus من خلا طبيعته الثجيرية والثجرية، إذ تراوح معدل ارتفاع أشجاره ما بين ( 5 - 9 ) م ـ ففي منطقتي زاويتا وسواره توكا تميز هذا النوع

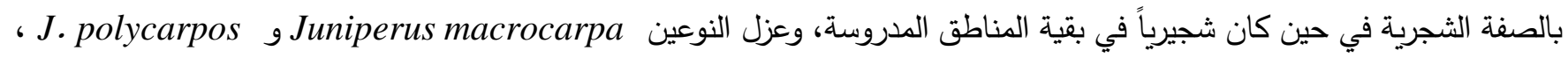
إذ كانا ذات طبيعة شجرية ،إذ بلغ معدل ارتفاع كل منهما (13 و 10.5) م على التوالي وكما هو موضح في الجدول ( 3 ) ، ويتضح

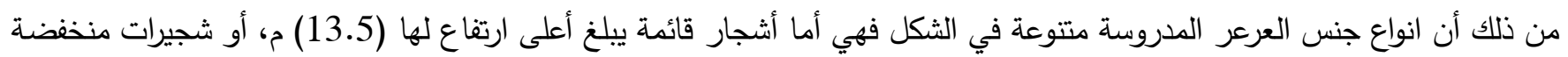

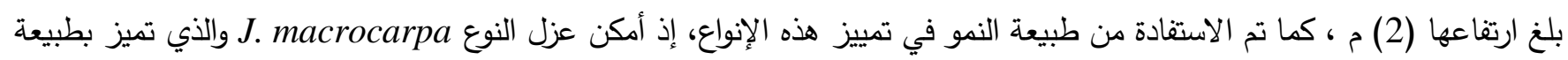

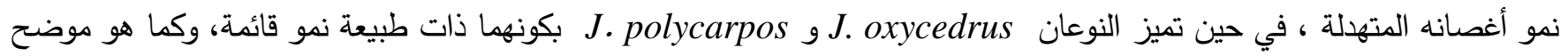
في الثكل ( 1 ) • ومن خلال الجولات الحقلية المتكررة لمواقع الدراسة المختلفة في المحافظات الثلاثة تبين وكما هو موضح في الجدول

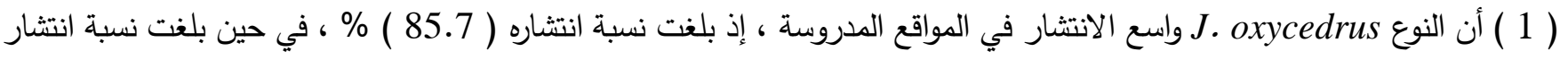

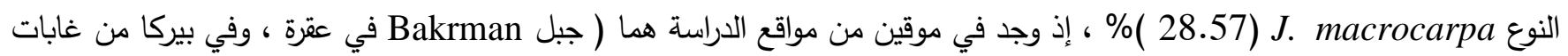

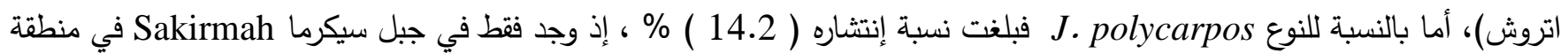
قره داغ في محافظة السليمانية.

\section{: Bark القشرة (القلف)}

يعّد أغلب الباحثين القشرة أو القلف Bark بأنها من أكثر الصفات أهمية في تشخيص الأشجار لا سيما عندما تكون الأوراق والفروع غير مساعدة لعملية التشخيص Harlow و Harrar [ 13 ] ، وقد كان الكساء السطحي لسلق أنواع العرعر المدروسة على شكل حراشف Scales متثققة في جميع الأنواع ألا أنها تباينت في سمك وعمق ونوع التشقق ولون القشرة وكما هو موضح في الجدول (3). إذ

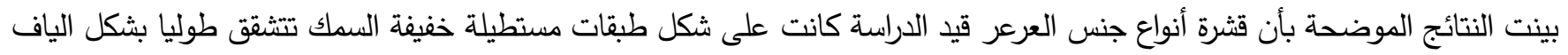
وكان لهذه الصفة اهمية تصنيفية في عزل الإنواع عن بعضها البعض، وكما هو موضح في الثكل ( 2 ). وقد توافقت هذه النتيجة مع لئح أكده Nicolle [14]، على اختلاف الوان القشرة في أنواع النباتات المختلفة وحتى ضمن النوع الواحد، ويعزى السبب لهذه التهان التباينات بين الإنواع Species في طبيعة القشرة الى الصفات الوراثية الخاصة بكل نوع وتاثير العوامل البيئية ، إذ أن كل نوع ممكن أن يتكيف للظروف ولتهن 


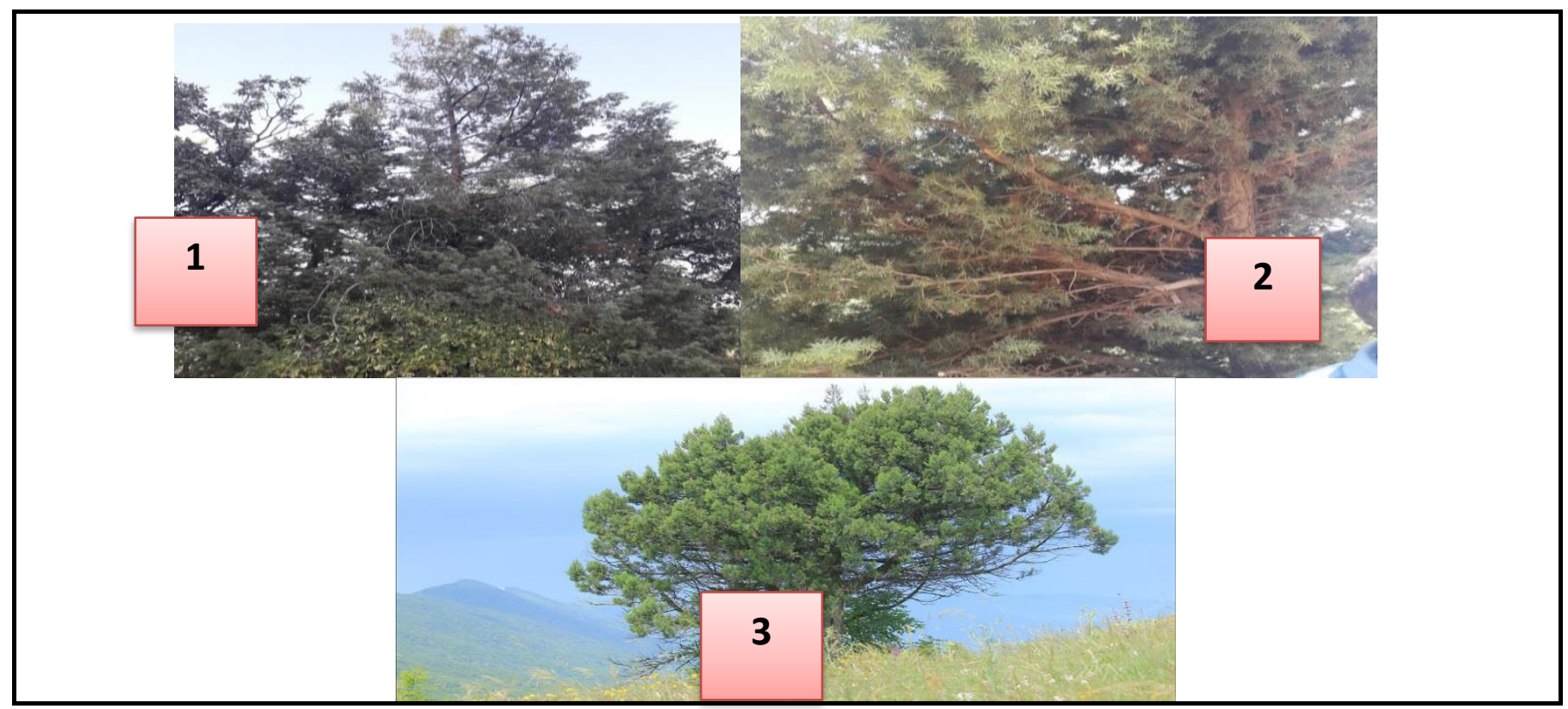

J.polycarpos $\quad-3 \quad$ J. macrocarpa -2 J. oxycedrus -1 : الثكل ( 1 ) طبيعة النمو لإنواع العرعر المدروسة

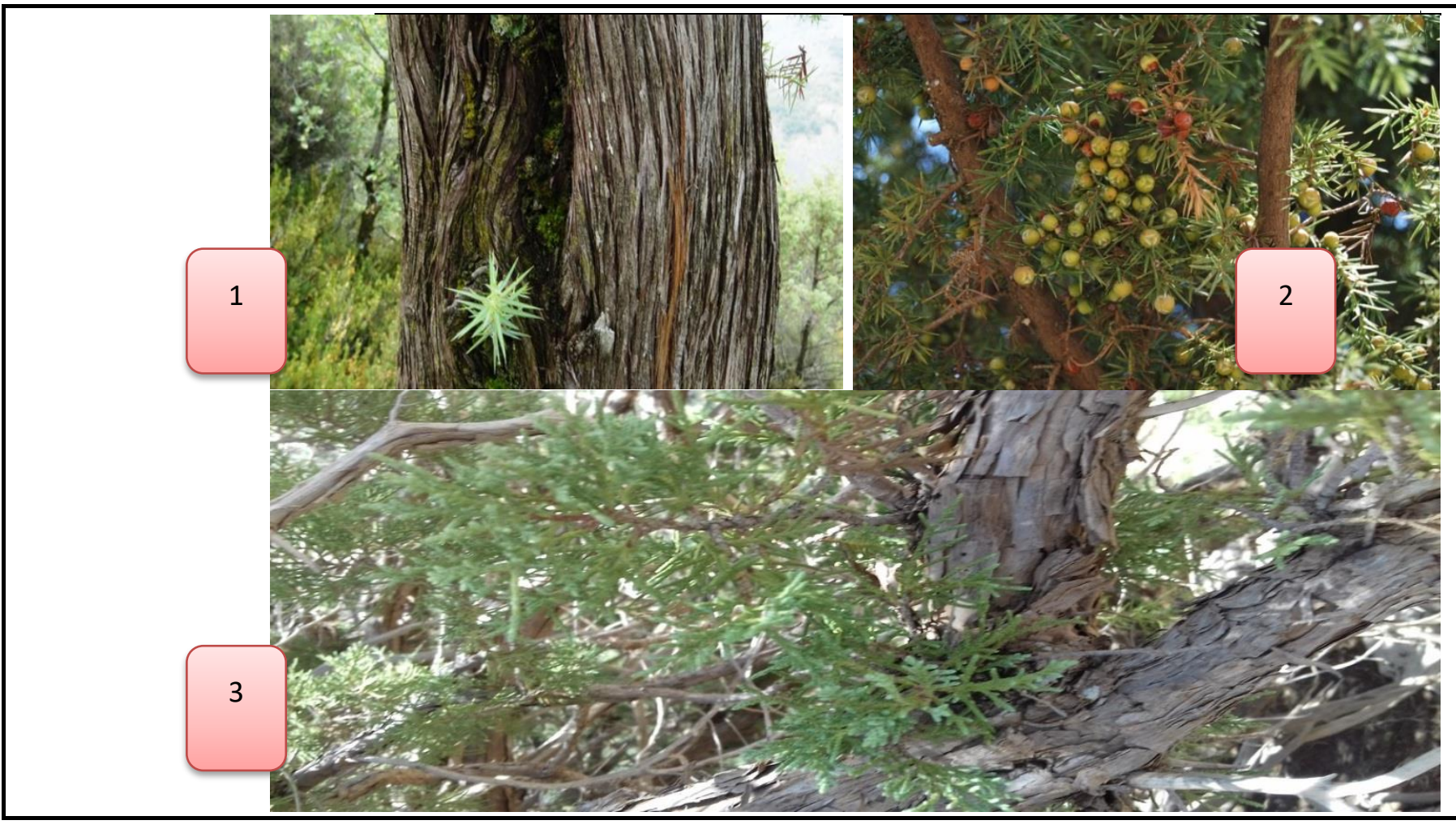

J. polycarpos -3

J. macrocarpa -2

J. oxycedrus -1 : الثكل ( 2 ) طبيعة ولون القلف لإنواع العرعر المدروسة 
: Needle Leaves : الأورلق الابرية

تميزت اوراق انواع العرعر الددروسة بنوعين من الأوراق وبذلك أمكن تقسيم الأنواع الى مجموعتين :

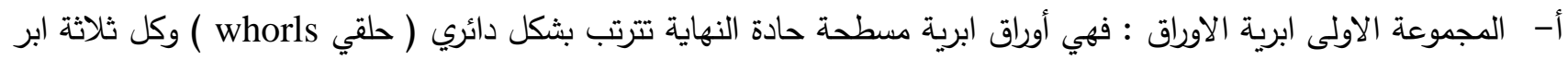

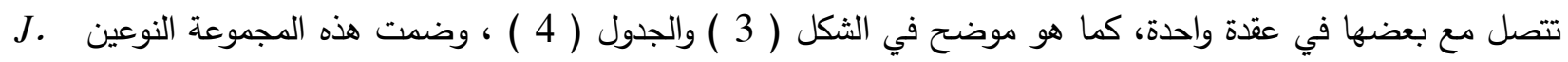
Juniperus macrocarpa g oxycedrus ب- المجموعة الثانية حرشفية الاوراق : ضمت النوع J polycarpos وكما هو موضح في الثكل ( 3 ) والثكل ( 4 ) .

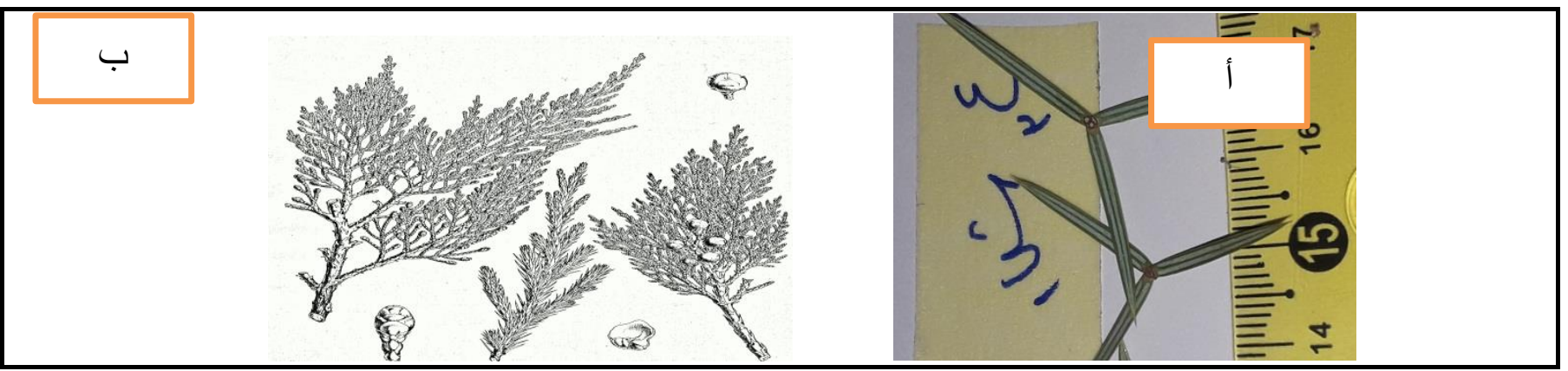

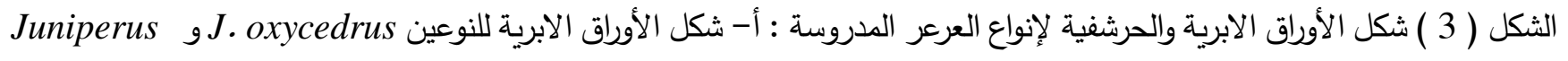
J. polycarpos macrocarpa 
Journal of Education and Science (ISSN 1812-125X), Vol: 29, No: 4, 2020 (154-176)

الجدول(3) ارتفاع الاشجار وطبيعة ولون القلف للأغصان والسيقان لأنواع جنس العرعر المدروسة

\begin{tabular}{|c|c|c|c|c|c|c|c|c|c|c|c|c|c|c|c|c|c|}
\hline \multicolumn{3}{|c|}{ لون قلف الاغصان } & \multicolumn{3}{|c|}{ لون القلف) } & \multicolumn{3}{|c|}{ طبيعة القشرة } & \multicolumn{2}{|c|}{ كثيافة الاغصلان } & \multicolumn{2}{|c|}{ ترتيب الأغصان } & \multicolumn{2}{|c|}{ طبيعة النمو } & \multirow{2}{*}{$\begin{array}{c}\text { ارتفاع الأشجار (م) } \\
\text { ( ) }\end{array}$} & \multirow{2}{*}{ 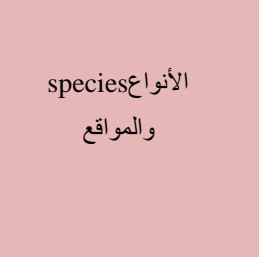 } & I. \\
\hline محر بني & ر فاتح & فاتح & محمر & بني & داكني & رقولية & شققوق & سميكة & منوسطة & 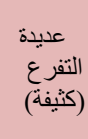 & متقابلة & متباللة & متهل & قائم & & & \\
\hline+ & & & & & + & & & + & + & & + & & & + & $\begin{array}{l}9-5 \\
(7.1)\end{array}$ & 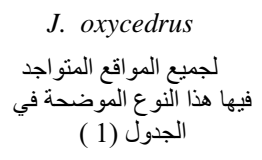 & 1 \\
\hline & + & & + & & & & + & & + & & + & & + & & $\begin{array}{c}13.5-12.5 \\
(13)\end{array}$ & $\begin{array}{c}\text { Juniperus } \\
\text { macrocarpa } \\
\text { عقرة(3) جبل بكرمان } 2 \text { واتروش }\end{array}$ & 2 \\
\hline & & + & & + & & + & & & & + & & + & & + & $(10.5)$ & $\begin{array}{l}\text { J. polycarpos } \\
\text { قره داغ(جبل دالبو) }\end{array}$ & 3 \\
\hline
\end{tabular}




\section{Journal of Education and Science (ISSN 1812-125X), Vol: 29, No: 4, 2020 (154-176)}

وبهذا قد تمت الاستفادة من صفة نوع الاوراق في تمييز الأنواع عن بعضها البعض. وبخصوص لون الأوراق قد تباينت

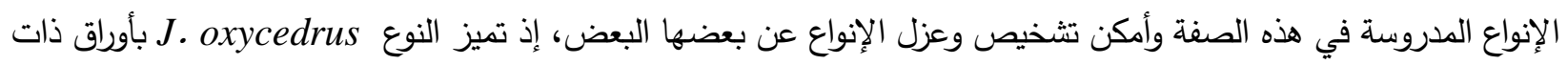
لون أخضر فاتح ، والصفة المميزة والبارزة والأكثر أهمية من الناحية التصنيفية لاوراق العرعر الثربين هي وجود خطين أبيضين رفيعين على سطح الورقة العلوي الذي تميز به هذا النوع كما هو موضح في الثكل ( 4 ) والجدول ( 4 ) ، في حين تميز

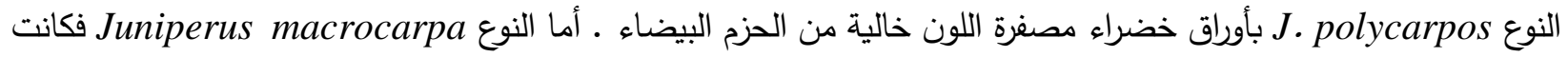
اوراقه ذات لون أخضر زاهي ، مع وجود خطين أبيضين عريضين بارزين في سطحها العلوي ، وكما هو موضح في الثكل (

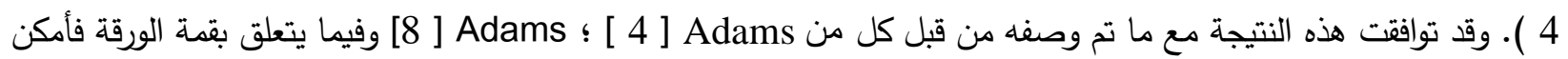
تميز ثلاثة انواع من القمة فأما ان تكون مستدقة Acuminate وكما هو الحال في النوع . oxycedrus . . او تكون حادة

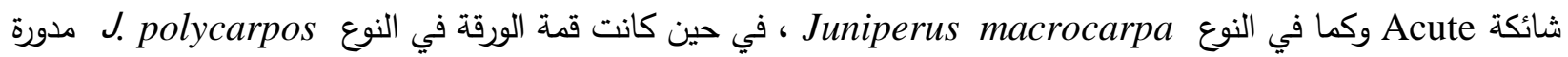
Juniperus أما قاعدة الورقة فكانت في النوع J. oxycedrus. macrocarpa دائرية عريضة ، وكانت في النوع Jolycarpos . poly مدورة رفيعة ، وكما هو موضح في الثكل ( 4 ). الجدول ( 4 ) الصفات النوعية لأوراق جنس العرعر المدروسة

\begin{tabular}{|c|c|c|c|c|c|c|}
\hline العلأمـات الفارقة & قمة الورقة & الورقة & الورقة & لونة الورقة & الإنواع & $ت$ \\
\hline وجود خطين ابيضين رفيعين على اللى العلورقة & مستدقة & فاعدة اللاتصال & ابرية & فاتح & J. oxycedrus & 1 \\
\hline بارزين على السطح العلين عريضين للورقة & حادة شـائكة & عريضة & ابرية & زاخير & J. macrocarpa & 2 \\
\hline عدم وجود أي خط & مدورة & مدورة & حرشفي & مصفر & J. polycarpos & 3 \\
\hline
\end{tabular}

أما الصفات الكمية لاوراق أنواع العرعر المدروسة فيوضحها الجدول ( 5 ) ، إذ تبين من الدراسة أن عدد الاوراق في العقدة الواحدة لم تكن لها اية اهمية تصنيفية تذكر بين النوعين العرعر الثربين والعرعر الكبير الثمار ، إذ كان عددها ( 3 ) اوراق في العقدة الواحدة في كلا النوعين ( الثكل 3 - أ )، في حين تميز النوع J. polycarpos . بوجود 2 او 3 وريقات في العقدة

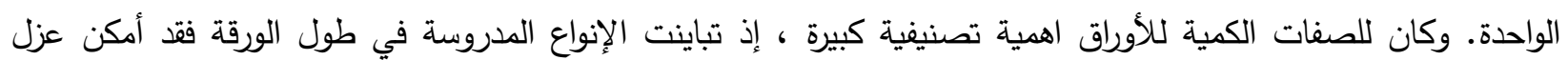
وتثخيص الإنواع الى مجموعتين وفقاً لطول الورقة:

أ- المجموعة الاولى ( قصيرة الأوراق ) : وشملت النوع . polycarpos والذي بلغ معدل طول ورقته (7.41) ملم ، وبذلك أمكن عزله وتشخيصه عن النوعين الاخرين بامتلاكه أقصر ورقة. ب- المجموعة الثانية ( طويلة الأوراق ): وشملت النوعين J. macrocarpa و oxycedrus ، إذ بلغ معدل طول اوراقهما ( 15.76 و 21.67 ) ملم على التوالي ، وبذلك تم تشخيص النوع لأمتلاكه لأطول ورقة 


\section{Journal of Education and Science (ISSN 1812-125X), Vol: 29, No: 4, 2020 (154-176)}

مقارنة بالنوعين الآخرين ، يليه العرعر الثربيني • وكما هو موضح في الثكل ( 4 ) الذي يبين ابعاد الاوراق للإنواع الثلاثة المدروسة.

أما عرض الورقة فهي صفة تصنيفية اخرى أمكن الاستفادة منها في تمييز الإنواع قيد الدراسة ، إذ بلغ معدل عرض ورقة .

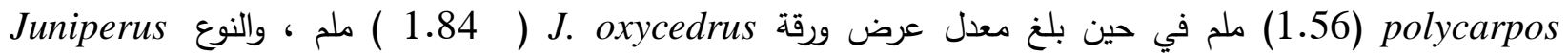
macrocarpa فهي أما سميكة نوعاً ما كما في النوعين Juniperus macrocarpa و . polycarpos إذ بلغ معدل سمك الورقة ( 1.29

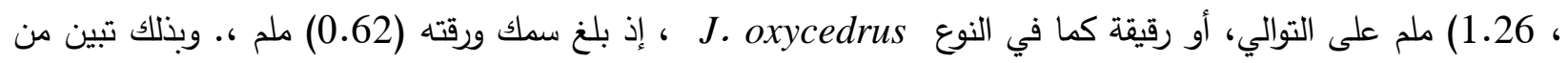
خلال نتائج دراسة الصفات المظهرية للأوراق ان النوع Juniperus macrocarpa تميز بأوراق أطول واعرض واسمك من

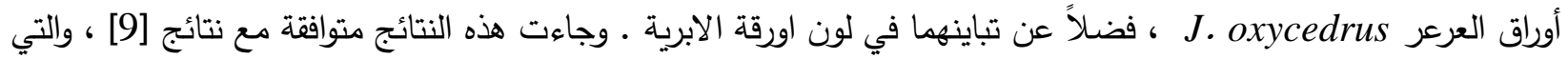
هدفت دراستهم إلى استكثاف مجموعة متتوعة من الخصائص المورفولوجية والتشريحية لنوعين مختلفين من العرعر هما (J.oxycedrus ون منطقة جبل Kopaniperus communis ) طول الورقة وعرضها وسمكها يتغيران بشكل ملحوظ بين النوعين • ومن خلا المقارنة تبين أن Juniperus communis بالنسبة إلى . Juniperus macrocarpa وجماعته [15 من حيث طول الورقة وعرضها للنوع Klimko

الجدول (5) الصفات الكمية لأوراق جنس العرعر المدروسة مقاسة بالمليمتر

\begin{tabular}{|c|c|c|c|c|c|}
\hline عدلد الأوراق في & سمك الورقة & عرض الورقة & طول الورقة & الإنواع & $ت$ \\
\hline 3 & $\begin{array}{c}0.76-0.53 \\
(0.66)\end{array}$ & $\begin{array}{c}2.08-1.68 \\
(1.97)\end{array}$ & $\begin{array}{c}14.51-11.25 \\
(13.20)\end{array}$ & $\begin{array}{c}\text { J. oxycedrus } \\
1 \varepsilon \\
1 ش\end{array}$ & 1 \\
\hline 3 & $\begin{array}{c}0.83-0.49 \\
(0.66)\end{array}$ & $\begin{array}{c}2.16-1.66 \\
(1.97)\end{array}$ & $\begin{array}{c}15.02-12.12 \\
(14.31)\end{array}$ & $\begin{array}{c}\text { J. oxycedrus } \\
1 \text { ع ع } 2\end{array}$ & 2 \\
\hline 3 & $\begin{array}{c}1.04-0.63 \\
(0.78) \\
\end{array}$ & $\begin{array}{c}2.60-1.18 \\
(1.92)\end{array}$ & $\begin{array}{c}20.54-17.67 \\
(20.22) \\
\end{array}$ & $\begin{array}{c}\text { J. oxycedrus } \\
1 \text { زش } \\
\end{array}$ & 3 \\
\hline 3 & $\begin{array}{c}0.72-0.30 \\
(0.47)\end{array}$ & $\begin{array}{c}1.85-1.15 \\
(1.54)\end{array}$ & $\begin{array}{c}18.40-15.61 \\
(15.63)\end{array}$ & $\begin{array}{c}\text { J. oxycedrus } \\
\text { س ش }\end{array}$ & 4 \\
\hline 3 & $\begin{array}{c}0.63-0.47 \\
(0.56)\end{array}$ & $\begin{array}{c}2.10-1.55 \\
(1.82)\end{array}$ & $\begin{array}{c}16.03-14.62 \\
(15.48)\end{array}$ & $\begin{array}{c}\text { J. oxycedrus } \\
1 \text { اتروش }\end{array}$ & 5 \\
\hline (3) & $(0.62)$ & $(1.84)$ & $(15.76)$ & المعدل & \\
\hline 3 & $\begin{array}{c}1.23-0.53 \\
(1.10)\end{array}$ & $\begin{array}{c}2.91-2.12 \\
(2.83)\end{array}$ & $\begin{array}{c}22.41-18.38 \\
(21.13)\end{array}$ & $\begin{array}{c}\text { J. macrocarpa } \\
1 ش \varepsilon \varepsilon\end{array}$ & 6 \\
\hline 3 & $\begin{array}{c}1.56-1.14 \\
(1.48)\end{array}$ & $\begin{array}{c}3.32-2.11 \\
(3.47) \\
\end{array}$ & $\begin{array}{c}22.47-18.34 \\
(22.21) \\
\end{array}$ & $\begin{array}{l}\text { J. macrocarpa } \\
1 \text { اتروش }\end{array}$ & 7 \\
\hline (3) & $(1.29)$ & $(3.15)$ & $(21.67)$ & المعدل & \\
\hline 2 او 3 & $\begin{array}{c}2.34-1.12 \\
(1.22)\end{array}$ & $\begin{array}{c}1.46-1.22 \\
(1.35)\end{array}$ & $\begin{array}{c}7.16-6.81 \\
(6.98) \\
\end{array}$ & $\begin{array}{c}\text { J. polycarpos } \\
\text { قرش1 }\end{array}$ & 8 \\
\hline 2او 3 & $\begin{array}{c}1.88-1.11 \\
(1.28)\end{array}$ & $\begin{array}{c}1.32-1.21 \\
(1.30)\end{array}$ & $\begin{array}{c}7.52-6.53 \\
(7.39) \\
\end{array}$ & $\begin{array}{c}\text { J. polycarpos } \\
2 \text { قرش }\end{array}$ & 9 \\
\hline 2 او 3 & $\begin{array}{c}1.33-1.28 \\
1.30 \\
\end{array}$ & $\begin{array}{c}1.97-1.76 \\
(1.89) \\
\end{array}$ & $\begin{array}{c}8.87-7.10 \\
(7.88) \\
\end{array}$ & $\begin{array}{c}\text { J. polycarpos } \\
3 \text { قرش }\end{array}$ & 10 \\
\hline 3 او 3 & $(1.26)$ & $(1.51)$ & $(7.41)$ & المعدل & \\
\hline
\end{tabular}




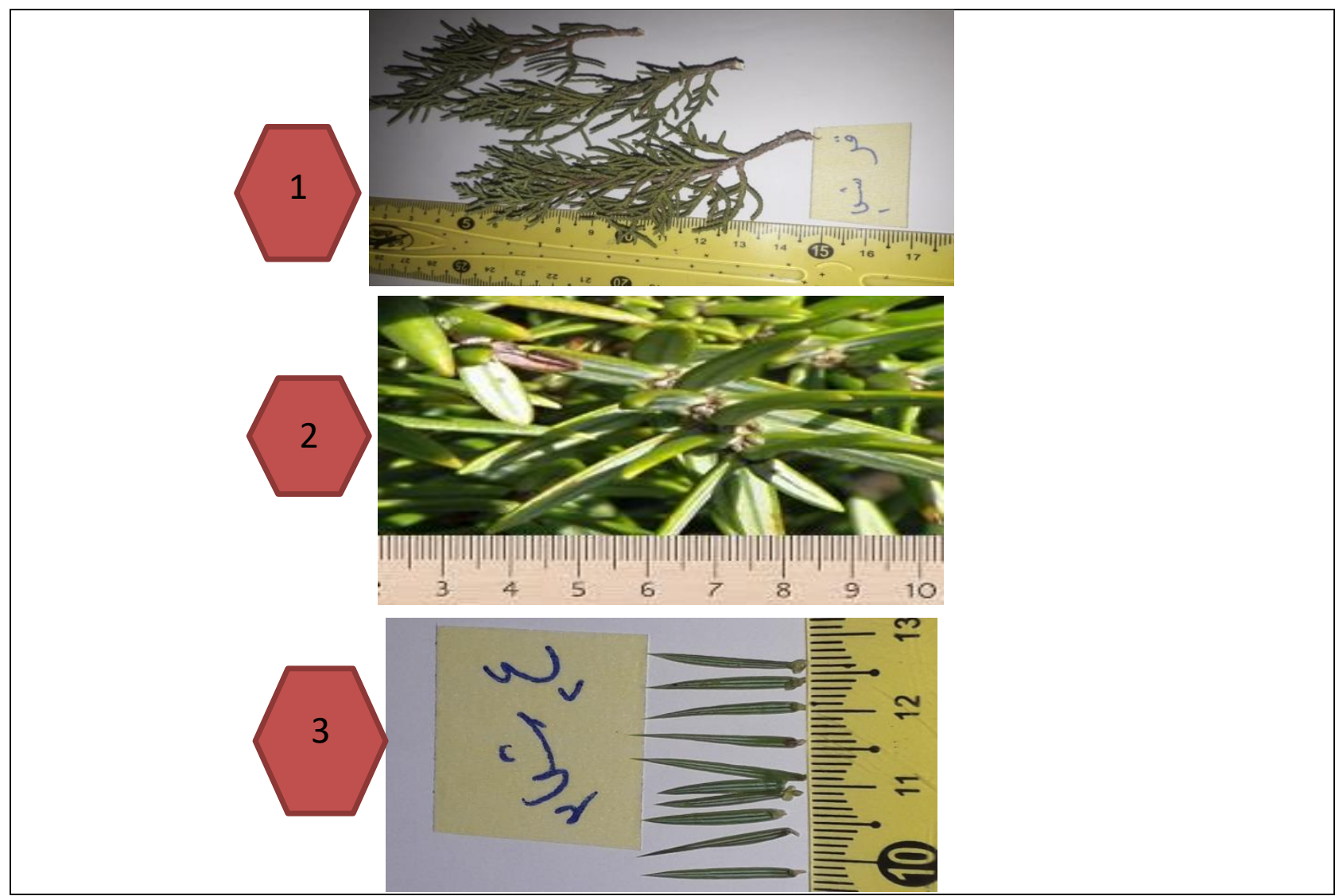

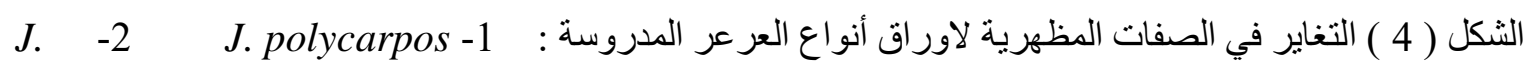
.J. oxycedrus - 3 macrocarpa

: Fruits الثمار

أظهرت الدراسة الحالية ان الصفات النوعية والكمية لثمار انواع العرعر الددروسة كانت واضحة وبارزة وساهمت مساهمة

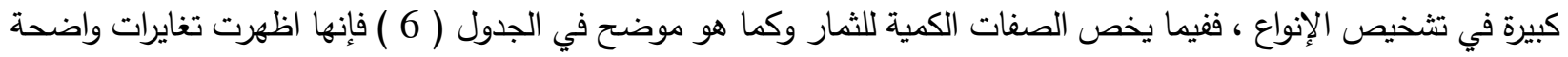

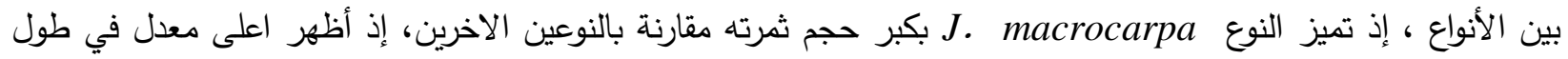

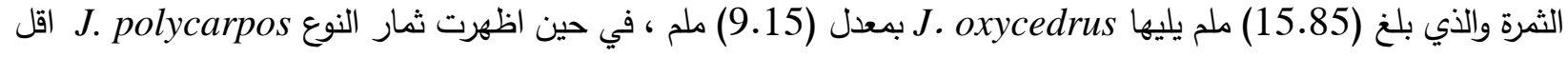

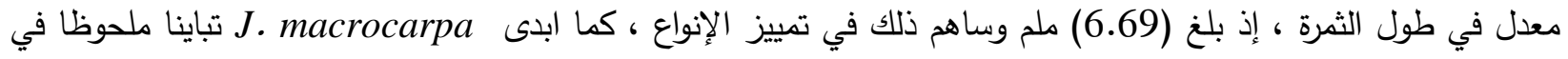

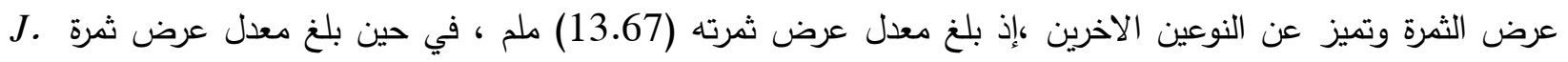
الت J oxycedrus

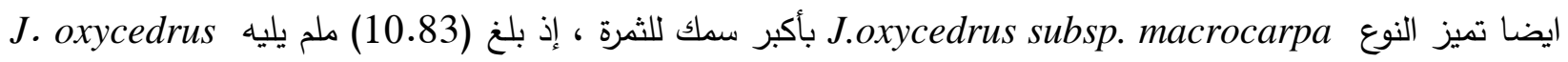

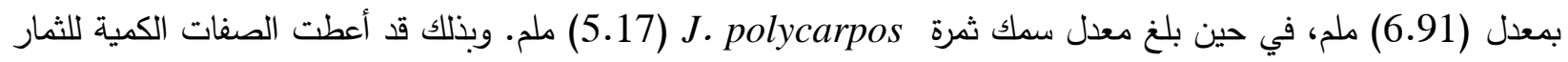

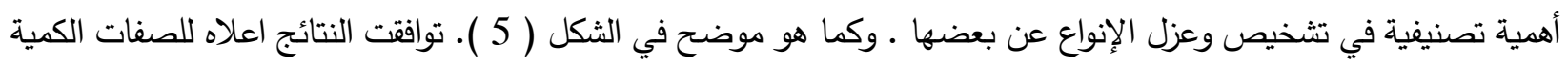

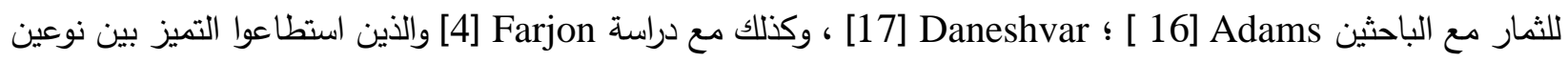


متثابهين كثيرا في الصفات المظهرية لنوعي العرعر Joetidissima . oxcelssa . foe عن طريق الثمار وعدد البذور في الثرة الواحدة وحجم المخاريط الذكرية .

الجدول (6) الصفات الكمية الخاصة بالثمار لإنواع جنس العرعر المدروسة والمقاسة بالملمتر •

\begin{tabular}{|c|c|c|c|c|}
\hline سمك الثمرة & عرض الثمرة & طول الثمرة & الإنواع & 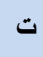 \\
\hline $\begin{array}{c}8.47-6.68 \\
(7.41)\end{array}$ & $\begin{array}{c}10.79-8.68 \\
(9.88)\end{array}$ & $\begin{array}{c}9.03-7.07 \\
(8.21)\end{array}$ & $\begin{array}{c}\text { J. oxycedrus } \\
1 \text { عاش }\end{array}$ & 1 \\
\hline $\begin{array}{c}7.99-6.05 \\
(6.91)\end{array}$ & $\begin{array}{c}10.31-8.38 \\
(9.43)\end{array}$ & $\begin{array}{c}9.77-7.90 \\
(8.59)\end{array}$ & $\begin{array}{c}\text { J. oxycedrus } \\
1 ش 2 \varepsilon\end{array}$ & 2 \\
\hline $\begin{array}{c}6.80-5.06 \\
(6.15)\end{array}$ & $\begin{array}{c}10.48-9.16 \\
(9.77)\end{array}$ & $\begin{array}{c}9.77-8.49 \\
(9.11)\end{array}$ & $\begin{array}{c}\text { J. oxycedrus } \\
\text { زشا }\end{array}$ & 3 \\
\hline $\begin{array}{c}8.44-6.90 \\
(7.42)\end{array}$ & $\begin{array}{l}11.13-8.95 \\
\quad(10.10)\end{array}$ & $\begin{array}{c}10.92-9.06 \\
(9.94)\end{array}$ & $\begin{array}{l}\text { J. oxycedrus } \\
\qquad س \text { ش1 }\end{array}$ & 4 \\
\hline $\begin{array}{c}8.67-4.95 \\
(6.70)\end{array}$ & $\begin{array}{c}11.17-9.52 \\
(10.26)\end{array}$ & $\begin{array}{c}11.55-9.30 \\
(10.35)\end{array}$ & $\begin{array}{l}\text { J. oxycedrus } \\
\qquad 1 \text { اتروش }\end{array}$ & 5 \\
\hline ( 6.91$)$ & ( 9.88$)$ & $(9.15)$ & المعدل & \\
\hline $\begin{array}{c}11.45-10.91 \\
(10.44)\end{array}$ & $\begin{array}{c}14.57-11.45 \\
(13.67)\end{array}$ & $\begin{array}{c}16.43-13.46 \\
(15.78)\end{array}$ & $\begin{array}{c}\text { J. macrocarpa } \\
1 ش 3 \varepsilon\end{array}$ & 6 \\
\hline $\begin{array}{c}12.77-9.79 \\
(11.23)\end{array}$ & $\begin{array}{c}14.27-12.66 \\
(13.68)\end{array}$ & $\begin{array}{c}16.11-14.24 \\
(15.92)\end{array}$ & $\begin{array}{c}\text { J. macrocarpa } \\
1 \text { اتروش } 1\end{array}$ & 7 \\
\hline ( 10.83$)$ & ( 13.67 ) & (15.85) & المعدل & \\
\hline $\begin{array}{c}6.62-5.15 \\
(5.77)\end{array}$ & $\begin{array}{c}9.01-6.78 \\
\quad(7.60)\end{array}$ & $\begin{array}{c}8.35-6.50 \\
\quad(7.47)\end{array}$ & $\begin{array}{c}\text { J. polycarpos } \\
1 \text { قر }\end{array}$ & 8 \\
\hline $\begin{array}{c}5.93-3.91 \\
(4.77)\end{array}$ & $\begin{array}{c}7.01-5.85 \\
(6.44)\end{array}$ & $\begin{array}{c}7.07-5.19 \\
(6.30)\end{array}$ & $\begin{array}{c}\text { J.polycarpos } \\
2 \text { قر }\end{array}$ & 9 \\
\hline $\begin{array}{c}6.24-4.06 \\
(4.98)\end{array}$ & $\begin{array}{c}7.39-4.96 \\
(6.14)\end{array}$ & $\begin{array}{c}7.70-5.75 \\
(6.30)\end{array}$ & $\begin{array}{c}\text { J. polycarpos } \\
3 \text { قر }\end{array}$ & 10 \\
\hline ( 5.17 ) & $(6.72)$ & ( 6.69$)$ & المعدل & \\
\hline
\end{tabular}

أما الصفات الاكثر بروزا والتي ساهمت في تمييز انواع العرعر فهي الصفات النوعية للثمار والتى أمكنت عزل الإنواع عن بعضها البعض فهي صفات بارزة ملحوظة للعين ويسهل مشاهدتها ، ومن اهم هذه الصفات النوعية هي وجود الفصوص على

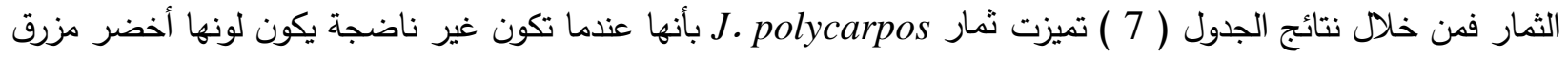
وعند النضج تصبح بنية غاهقة وشكلها كروي وتكون ملساء وتتميز بعدم وجود الفصوص على الثمرة ، وتغطيتها بمادة بيضاء اللون مع وجود نتوء بارز في قمة الثمرة ، وكما هو موضح في الثكل ( 5 )، وهذا ميزها عن ثمار النوعين الاخرين فهي

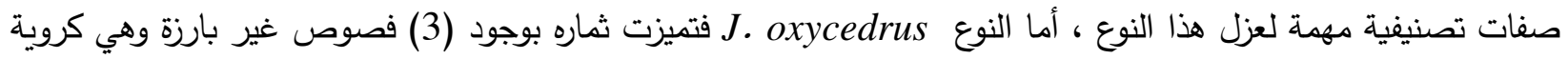
مفصصة يكون لونها أخضر قبل النضج ليصبح بني محمر عند النضج ، في حين تميزت ثمار النوع J. macrocarpa باللون 
ألأخضر المصفر قبل النضج وتصبح برتقالي - أحمر عند النضج وبشكلها الكروي أو البيضي المفصص مع وجود (3) فصوص بارزة والتي توضح شكل ولون وثمار الإنواع المدروسة.

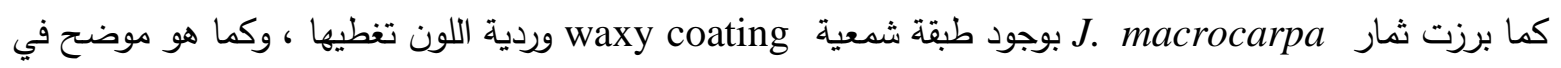

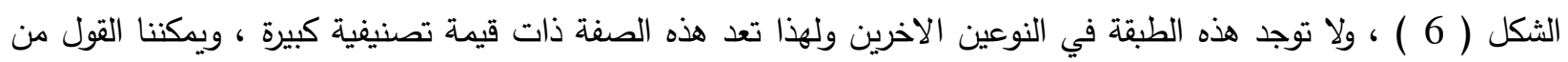
خلال نتائج دراسة تغايرات الثمار بأنها يمكن ان تقسم الإنواع المدروسة الى مجموعتبين ضمت المجموعة الاولى ثمار غير

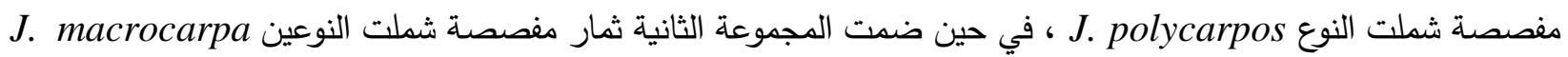
و oxycedrus . oxyc وكما هو موضح في الثكل ( 6 ) • وجاءت هذه النتائج متوافقة مع نتائج Daneshvar [ 17 ] عند دراسته

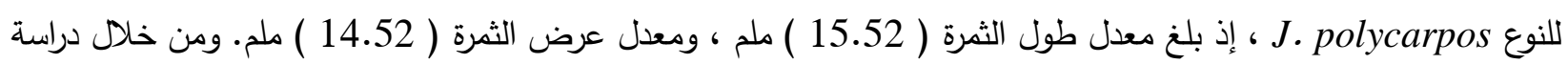
التغايرات النوعية والكمية لثمار أنواع جنس العرعر قيد الدراسة تبين وجود تغايرات واضحة ذات إدات قيمة تصنيفية بالغة الأهمية لتمييز هذه الإنواع عن بعضها ، ويعود سبب هذه الاهمية التصنيفية الكبيرة للثمار الى ثباتها أمام التغيرات والظروف البيائية اولاً

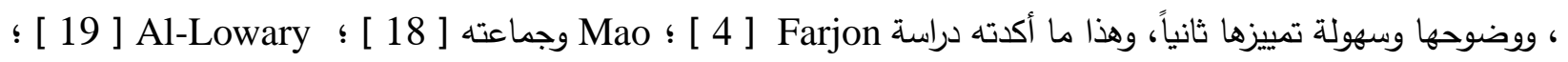

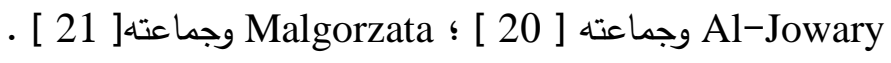

الجدول ( 7 ) الصفات النوعية لثمار أنواع العرعر المدروسة

\begin{tabular}{|c|c|c|c|c|c|}
\hline العلأمات الفارقة & ش مل الثمرة & لون الثمرة بعد & لون الثمرة قبل النضج & الأنواع & ت \\
\hline وجود 3 فصوصة & كروي مفصص & بني محمر & أخضر & J. oxycedrus & 1 \\
\hline بارزة مع وجود 3 فصود طبقة & كروي أو بيضي & برتقالي ـ الاحمر & أخضر مصفر & J. .macrocarpa & 2 \\
\hline مع وجود مادة بيضاء & كروية ملساء & 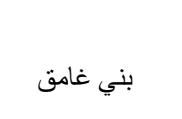 & أخضر مزرق & J. polycarpos & 3 \\
\hline
\end{tabular}




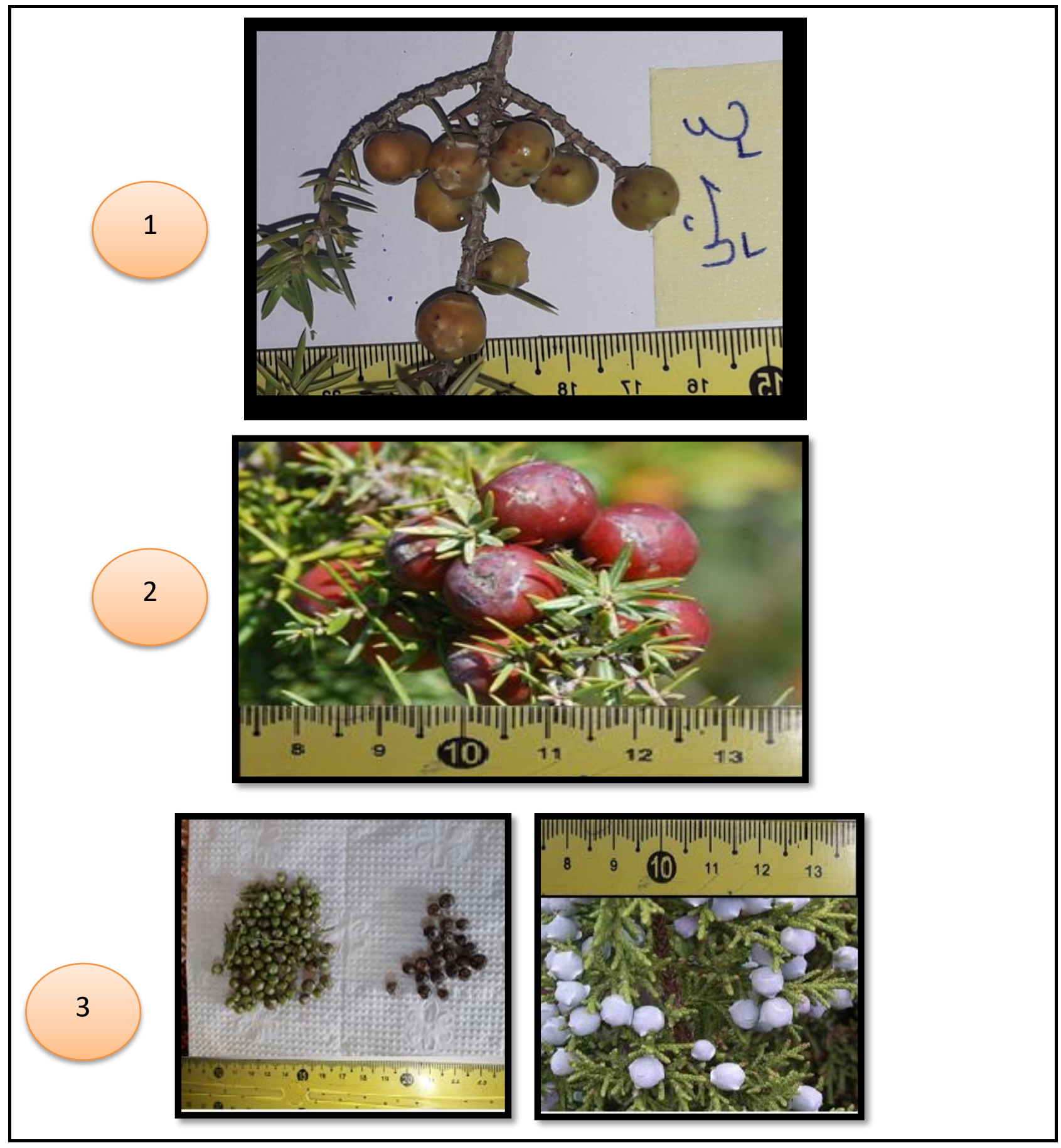

J. macrocarpa -2 J. oxycedrus - - الثكل ( 5 ) ) التغاير في الصفات المظهرية لثمار أنواع العرعر المدروسة J. polycarpos -3 


\section{5- البذور Seeds :}

بينت نتائج الجدول ( 8 ) بان الصفات النوعية للبذور ساهمت بثكل فعال في تشخيص وعزل الإنواع عن بعضها ، فقد أمكن تميز مجموعتين من النباتات العائدة للعرعر وفقاً لشكل البذرة ، فالمجموعة الاولى ضمت بذوراً بيضوية الثكل الى بيضية

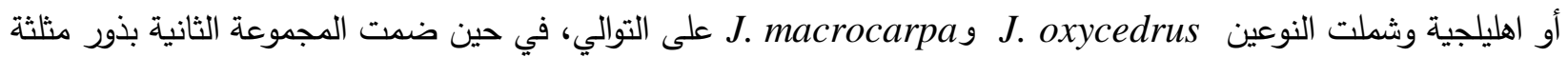

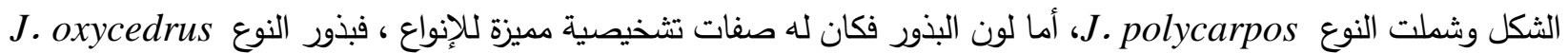

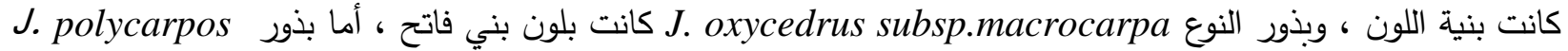
فكانت بنية داكنة ،وكما هو موضح في الثكل ( 6 فون ) . الجدول ( 8 ) الصفات النوعية لبذور أنواع العرعر المدروسة

\begin{tabular}{|c|c|c|c|c|}
\hline عدد البذور في الثمرة & لون البذرة & شكل البذرة & الانواع species & ت \\
\hline $3-2$ & بني & بيضية & J. oxycedrus & 1 \\
\hline $4-2$ & بني فاتح & بيضية - إهليلجية & J. macrocarpa & 2 \\
\hline 3 & بني داكن & مثلثة & J. polycarpos & 3 \\
\hline
\end{tabular}

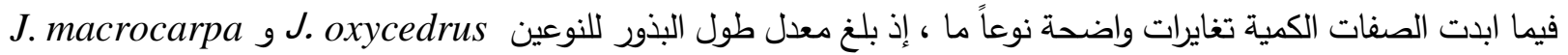
تقاربا في طولها ، إذ بلغت (6.26 - 6.35 ) ملم على التوالي ، في حين اظهرت بذور النوع J polycarpos معدلا اقل في طول البذرة بلغت (4.16) ملم • وكان لمعدل عرض البذور قيمة تصنيفية ، إذ تميز النوعJ. macrocarpa بعرض بذرته

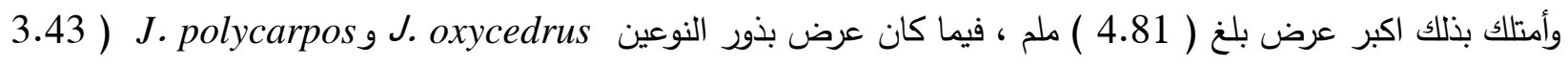

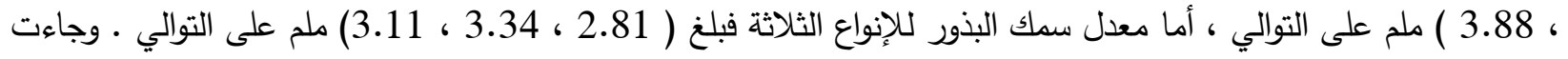
هذه النتائج متوافقة مع دراسة Adams [ 22 ] عند دراسته للتباين التصنيفي والجغرافي للعرعر الفينيقي Joenicea وأنواع أخرى من العرعر حيث استخدم الخصائص المورفولوجية للمخاريط الانثوية Cones والبذور Seeds والبراعم ذات الأوراق الابرية والتمييز بينها في مناطق حوض البحر المتوسط . وبينت نتائجهم ان هناك اختلافات واضحة في حجم المخاريط بين

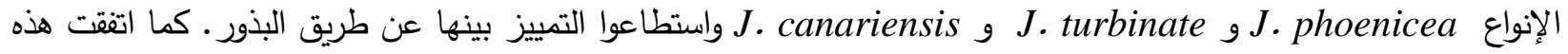
النتائج مع نتائج دراسة Klimko الإنواع من ( 2 - 3) بذور ما عدا النوع ذو الثمار الكبيرة فتراوح عدد بذوره ما بين ( 2-4 )، وكما موضح في الجدول ( 9 ( ) 
Journal of Education and Science (ISSN 1812-125X), Vol: 29, No: 4, 2020 (154-176)

الجدول ( 9 ) الصفات الكمية لبذور أنواع جنس العرعر المدروسة مقاسة بالملمتر

\begin{tabular}{|c|c|c|c|c|}
\hline سمك البذرة & عرض البذرة & طول البذرة & الإنواعPecies & ت \\
\hline $\begin{array}{c}3.08-2.35 \\
(2.63)\end{array}$ & $\begin{array}{c}3.67-3.03 \\
(3.38)\end{array}$ & $\begin{array}{c}6.36-4.84 \\
\quad(5.77)\end{array}$ & $\begin{array}{c}\text { J. oxycedrus } \\
1 \varepsilon\end{array}$ & 1 \\
\hline $\begin{array}{c}3.46-2.65 \\
(3.03)\end{array}$ & $\begin{array}{c}5.57-3.97 \\
(3.85)\end{array}$ & $\begin{array}{c}6.38-5.45 \\
(6.06)\end{array}$ & $\begin{array}{c}\text { J. oxycedrus } \\
2 \varepsilon\end{array}$ & 2 \\
\hline $\begin{array}{c}3.02-2.30 \\
(2.65)\end{array}$ & $\begin{array}{c}3.41-2.72 \\
(3.04)\end{array}$ & $\begin{array}{c}6.46-5.60 \\
(6.09)\end{array}$ & $\begin{array}{c}\text { J. oxycedrus } \\
j\end{array}$ & 3 \\
\hline $\begin{array}{c}3.14-2.38 \\
(2.69)\end{array}$ & $\begin{array}{c}3.68-2.91 \\
(3.24)\end{array}$ & $\begin{array}{c}6.75-5.84 \\
\quad(6.23)\end{array}$ & $\begin{array}{c}\text { J. oxycedrus } \\
\text { w }\end{array}$ & 4 \\
\hline $\begin{array}{c}3.24-2.83 \\
(3.05)\end{array}$ & $\begin{array}{c}3.99-3.42 \\
(3.65)\end{array}$ & $\begin{array}{c}9.96-5.85 \\
(7.16)\end{array}$ & $\begin{array}{c}\text { J. oxycedrus } \\
\text { اتروش }\end{array}$ & 5 \\
\hline$(2.81)$ & ( 3.43$)$ & $(6.26)$ & \multicolumn{2}{|l|}{ المعدل } \\
\hline $\begin{array}{c}3.22-2.42 \\
(3.01)\end{array}$ & $\begin{array}{c}4.17-4.33 \\
\quad(4.20)\end{array}$ & $\begin{array}{c}6.55-5.90 \\
(6.25)\end{array}$ & $\begin{array}{c}J . \text { macrocarpa } \\
3 \varepsilon\end{array}$ & 6 \\
\hline $\begin{array}{l}3.85-3.11 \\
\quad(3.67)\end{array}$ & $\begin{array}{l}5.87-5.23 \\
\quad(5.42)\end{array}$ & $\begin{array}{c}6.98-6.23 \\
(6.46)\end{array}$ & $\begin{array}{c}\text { J. macrocarpa } \\
\text { اتروش }\end{array}$ & 7 \\
\hline$(3.34)$ & $(4.81)$ & $(6.35)$ & \multicolumn{2}{|l|}{ المعدل } \\
\hline $\begin{array}{c}4.57-2.30 \\
(3.21) \\
\end{array}$ & $\begin{array}{c}5.21-3.57 \\
(4.06) \\
\end{array}$ & $\begin{array}{c}5.82-3.76 \\
(4.37) \\
\end{array}$ & $\begin{array}{c}\text { J. polycarpos } \\
1 ق 1 \\
\end{array}$ & 8 \\
\hline $\begin{array}{c}3.75-2.37 \\
(2.92)\end{array}$ & $\begin{array}{c}4.67-3.25 \\
(3.95)\end{array}$ & $\begin{array}{c}4.99-3.19 \\
(4.11)\end{array}$ & $\begin{array}{c}\text { J. polycarpos } \\
2 ق 2\end{array}$ & 9 \\
\hline $\begin{array}{c}343-2.53 \\
(3.22)\end{array}$ & $\begin{array}{c}4.14-3.07 \\
(3.65)\end{array}$ & $\begin{array}{c}4.57-3.06 \\
(4.01)\end{array}$ & $\begin{array}{c}\text { J. polycarpos } \\
3 \text { ق }\end{array}$ & 10 \\
\hline ( 3.11$)$ & ( 3.88$)$ & $(4.16)$ & المعدل & \\
\hline
\end{tabular}




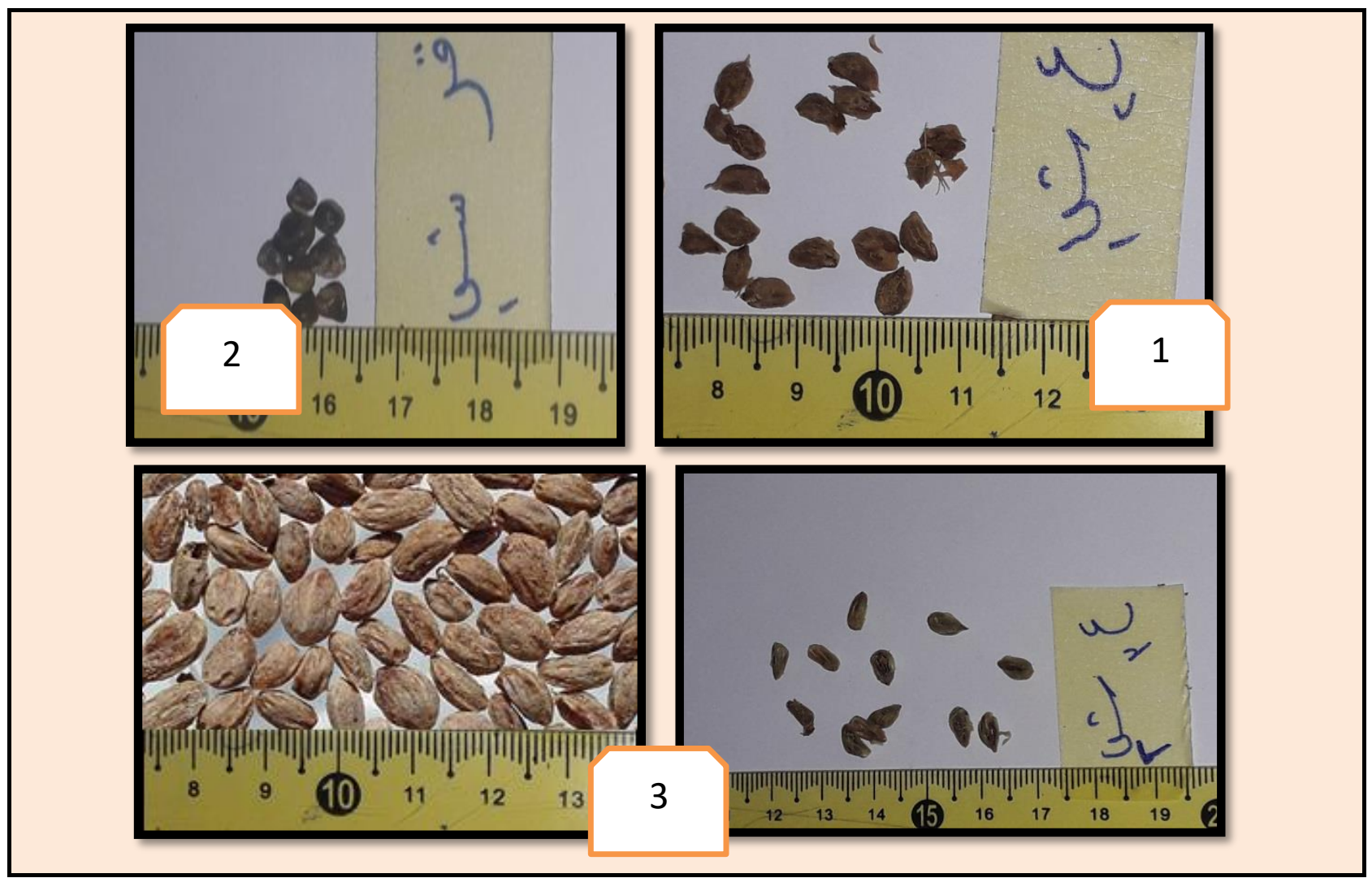

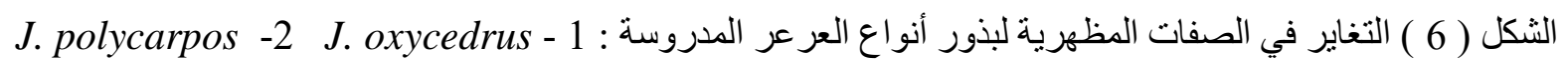
J. macrocarpa -3

6- النظام الزهري لجنس العرعر: Inflorescence

Male cones 1-6

يظهر من الجدول ( 10 ) الخاص بالصفات النوعية لمخاريط الإنواع المدروسة اختلافاً واضحاً بين هذه الإنواع والتي تم الاستفادة منها في تشخيص كل نوع إستتادً الى مخاريطه الذكرية ، إذ أمكن تشخيص مجموعتين من الإنواع وفقاً للمخاريط : المجموعة الاولى نباتات وحيدة

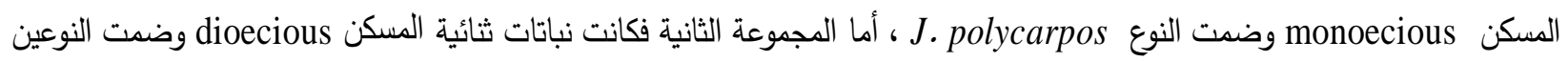

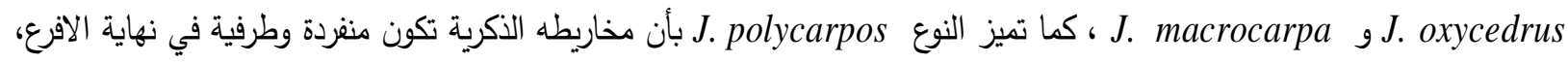
في حين تتوزع المخاريط الذكرية للنوعين الآخرين على طول الغصن ، وكما هو موضح في الثكل ( 7 )، وقد توافقت هذه النتيجة مع ماتوصل

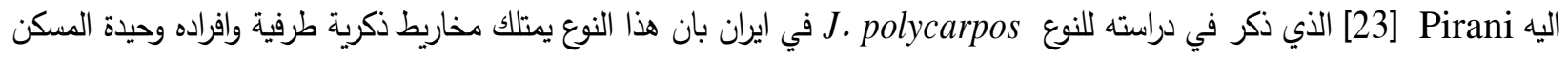
monoecious يتعلق بشكل المخروط الذكري تميز النوع J. oxycedrus بأن مخروطة كان بيضي الثكل ، في حين كان شكل مخروط العرعر الكبير الثمار كروي ، أما مخروط النوع .polycarpos . فكان ذو شكل بيضي متطاول ـ وبخصوص لون المخاريط فكان اصفر قبل النضج ليصبح J. macrocarpa لني مصفر بعد النضج للنوع العرعر الشربين ، وأخضر مصفر قبل النضج ليصبح قهوائي مصفر بعد النضج اللعرعر ك. oxycedrus subsp. polycarpos ، برتقالي قبل النضج ليتحول الى اصفر محمر بعد النضج . الجدول ( 10 ) الصفات النوعية للمخاريط الذكرية لانواع جنس العرعر المدروسة 
Journal of Education and Science (ISSN 1812-125X), Vol: 29, No: 4, 2020 (154-176)

\begin{tabular}{|c|c|c|c|c|c|c|}
\hline المخاريط على الغصن & الجنسي النبات & $\begin{array}{c}\text { المخروط بعد النضج } \\
\text { الون }\end{array}$ & المخروط قبل & شكل المخروط & الأنواع & ت ت \\
\hline طول الغصن على & $\begin{array}{l}\text { تثنائي المسكن } \\
\text { dioecious }\end{array}$ & بني مصفر & اصفر & بيضي & J. oxycedrus & 1 \\
\hline طول الغصن على & $\begin{array}{l}\text { تثنائي المسكن Dioecious } \\
\text { تمن }\end{array}$ & قهو ائي مصفر & أخضر مصفر & كروي & $\begin{array}{c}J . \\
\text { macrocarpa }\end{array}$ & 2 \\
\hline طرفية & $\begin{array}{c}\text { وحيد المسكن } \\
\text { monoecious }\end{array}$ & اصفر محمر & برتقالي & بيضي منطاول & $\begin{array}{c}J . \\
\text { polycarpos }\end{array}$ & 3 \\
\hline
\end{tabular}

أما الصفات الكمية للمخاريط الذكرية والموضحة في الجدول ( 11 ) فلم تظهر فروقات كبيرة بين الإنواع ، إذ بلغ معدل طول مخاريط

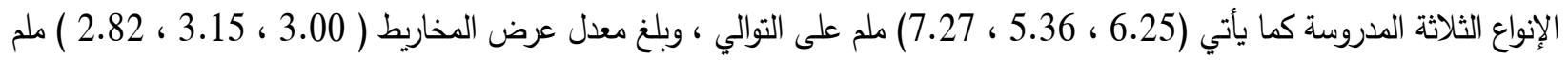

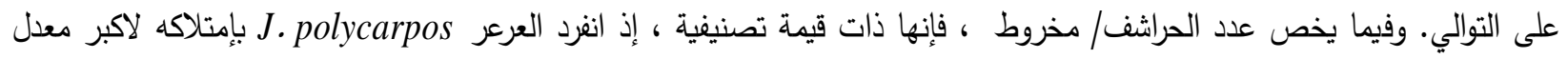
مقارنة بالنوعين الآخرين ، إذ بلغ معدله ( 17.08 ) ، يليه النوع Jacrocarpa بمعدل بلغ ( 15.81 ) .أما أقل معدل فتميز به العرعر الثربين إذ بلغ ( 10.76 ) .

الجدول ( 11 ) الصفات الكمية للمخاريط الذكرية لانواع جنس العرعر المدروسة والمقاسة بالملمتر

\begin{tabular}{|c|c|c|c|c|}
\hline عدد الحر اشف/ مخروط & عرض المخروط & طول المخروط & $\begin{array}{l}\text { الأنواع } \\
\text { Species }\end{array}$ & ت \\
\hline $\begin{array}{c}12-8 \\
(10.40) \\
\end{array}$ & $\begin{array}{c}3.03-2.17 \\
(2.75) \\
\end{array}$ & $\begin{array}{c}6.71-4.90 \\
(5.96) \\
\end{array}$ & $\begin{array}{c}\text { J. oxycedrus } \\
1 \varepsilon \\
\end{array}$ & 1 \\
\hline $\begin{array}{l}11-9.5 \\
(10.5) \\
\end{array}$ & $\begin{array}{c}3.88-2.59 \\
(3.52)\end{array}$ & $\begin{array}{c}8.02-5.88 \\
(6.65) \\
\end{array}$ & $\begin{array}{c}\text { J. oxycedrus } \\
2 \varepsilon\end{array}$ & 2 \\
\hline $\begin{array}{l}12-9.5 \\
(11.3)\end{array}$ & $\begin{array}{c}3.47-2.30 \\
(2.92)\end{array}$ & $\begin{array}{c}6.78-5.16 \\
(6.14)\end{array}$ & $\begin{array}{c}\text { J. oxycedrus } \\
j\end{array}$ & 3 \\
\hline $\begin{array}{l}11.5-9 \\
(10.4)\end{array}$ & $\begin{array}{c}3.77-2.83 \\
(3.38)\end{array}$ & $\begin{array}{c}8.19-5.86 \\
(6.94)\end{array}$ & $\begin{array}{c}\text { J. oxycedrus } \\
\mathrm{w}\end{array}$ & 4 \\
\hline $\begin{array}{c}10-8.5 \\
(11.2)\end{array}$ & $\begin{array}{c}2.89-2.13 \\
(2.46) \\
\end{array}$ & $\begin{array}{c}6.53-4.79 \\
(5.58) \\
\end{array}$ & $\begin{array}{c}\text { J. oxycedrus } \\
\text { اتروش }\end{array}$ & 5 \\
\hline$(10.76)$ & (3.00) & $(6.25)$ & المعل ل المل & \\
\hline $\begin{array}{c}17-15 \\
(16.51) \\
\end{array}$ & $\begin{array}{c}3.66-2.32 \\
(3.09)\end{array}$ & $\begin{array}{c}7.77-5.58 \\
(6.46)\end{array}$ & $\begin{array}{c}\text { J. macrocarpa } \\
3 \varepsilon\end{array}$ & 6 \\
\hline $\begin{array}{l}17-15 \\
(15.46)\end{array}$ & $\begin{array}{c}3.89-2.78 \\
(3.21)\end{array}$ & $\begin{array}{c}4.78-4.11 \\
(4.26)\end{array}$ & $\begin{array}{c}\text { J. macrocarpa } \\
\text { اتروش }\end{array}$ & 7 \\
\hline ( 15.98$)$ & (3.15) & $(5.36)$ & المعل ل & \\
\hline $\begin{array}{l}17 .-14 \\
(16.85)\end{array}$ & $\begin{array}{c}4.1-2.2 \\
(3.02)\end{array}$ & $\begin{array}{c}7.89-6.67 \\
(7.23)\end{array}$ & $\begin{array}{c}\text { J. polycarpos } \\
1 \text { ق }\end{array}$ & 8 \\
\hline $\begin{array}{c}17-15 \\
(17.10)\end{array}$ & $\begin{array}{c}3.6-1.8 \\
(2.34)\end{array}$ & $\begin{array}{c}7.49-6.88 \\
(.7 .12)\end{array}$ & $\begin{array}{c}\text { J. polycarpos } \\
2 \operatorname{\theta }^{\circ}\end{array}$ & 9 \\
\hline $\begin{array}{l}17-16 \\
(17.31)\end{array}$ & $\begin{array}{c}4.21-2.3 \\
(3.10)\end{array}$ & $\begin{array}{c}7.86-6.5 \\
(7.46) \\
\end{array}$ & $\begin{array}{c}\text { J. polycarpos } \\
3 ر\end{array}$ & 10 \\
\hline ( 17.08$)$ & $(2.82)$ & (7.27) & المعل ل المل & \\
\hline
\end{tabular}



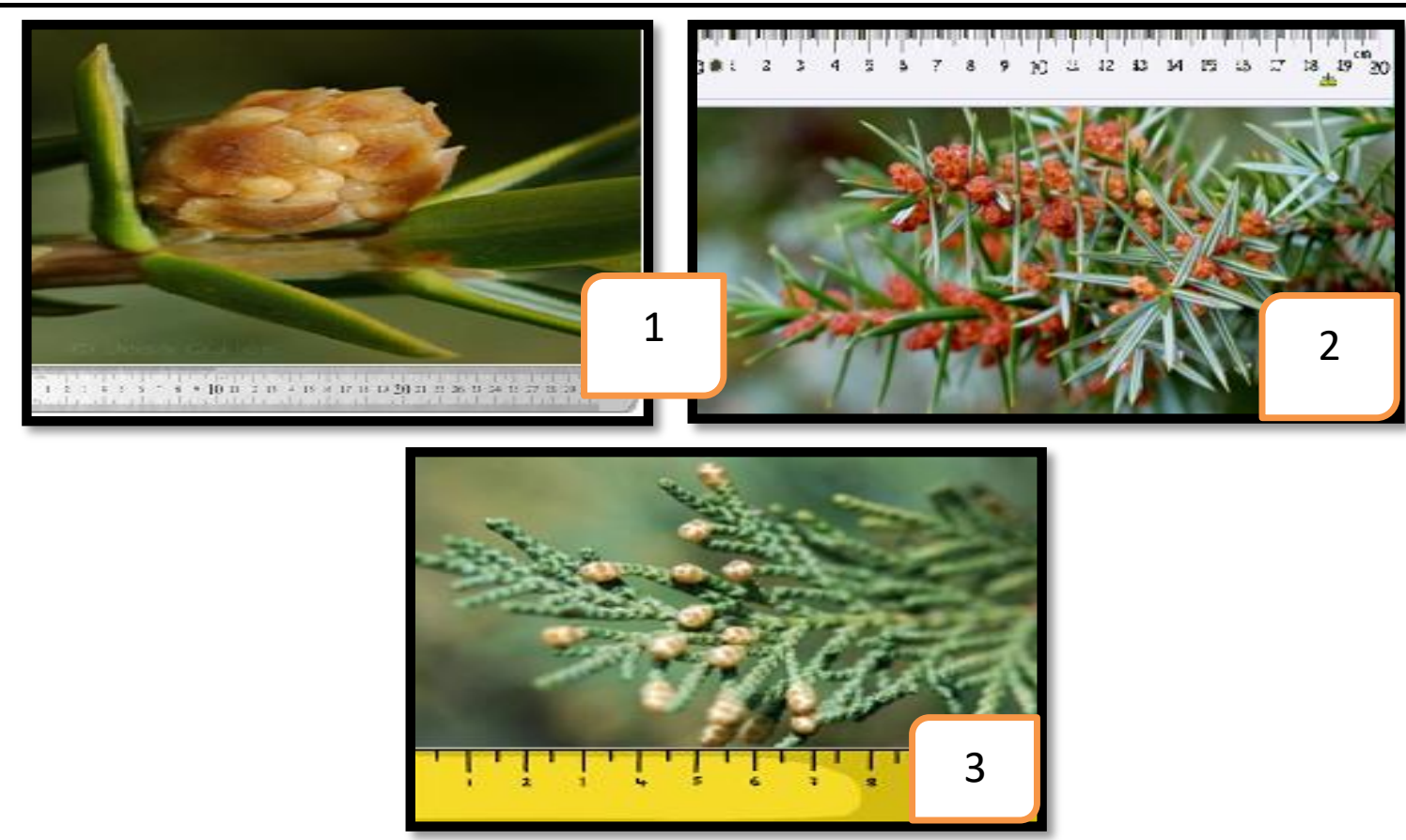

J. oxycedrus -1 : الثكل ( 7 ) التغاير في الصفات المظهرية للمخاريط الذكرية لإنواع العرعر المدروسة . J. polycarpos - 3 J. macrocarpa

Flower buds : 6

عند دراستتا للصفات الكمية والنوعية للبراعم الزهرية للأنواع المدروسة ( الجدولين 12و 13) ، تبين انها ذات قيمة تصنيفية معتبرة في تثخيص هذه الإنواع ـ ففيما يتعلق بالصفات النوعية أمكن تمييز البراعم الزهرية من خلال لون الاسدية فكان

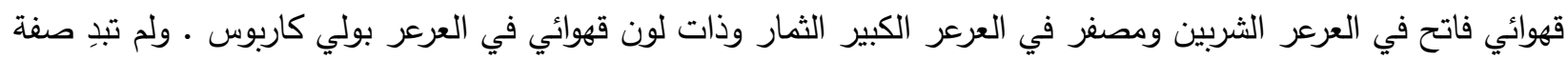
نوع البتلات ولون اوراق الكاس وعدد البتلات وعدد الاسدية اي اهمية تصنيفية بين الأنواع المدروسة ، فقد كانت جميع الإنواع ملتحمة البتلات، والاوراق الكأسية كانت خضراء اللون ، وعدد البتلات وعدد اوراق الكاس كانت (3) في جميع الإنواع المدروسة ، وكما هو موضح في الثكل ( 8 ) • وبذلك لم تكن لهذه الصفات اي دور في عزل الإنواع عن بعضها البعض . الجدول ( 12 ) الصفات النوعية للبراعم الزهرية لانواع جنس العرعر قيد الدراسه

\begin{tabular}{|c|c|c|c|c|}
\hline لون اوراق الكأس & لون الاسدية & نوع البتلات & الأنواع & ت \\
\hline أخضر & قهوائي فاتح & ملتحمة & J. oxycedrus. & 1 \\
\hline أخضر & مصفر & ملتحمة & J. macrocarpa & 2 \\
\hline أخضر & قهوائي & ملتحمة & J. polycarpos & 3 \\
\hline
\end{tabular}

أما الصفات الكمية للبراعم الزهرية فقد ابدت الإنواع تغايراً ملحوظاً وخاصة فيما يتعلق بطول البرعم الزهري، زكما هو موضح في الجدول ( 13 ) ، إذ بلغ معدله في النوع العرعر الثربين( 13.68) ملم ، وفي العرعر الكبير الثمار بلغ معدله (15.42)

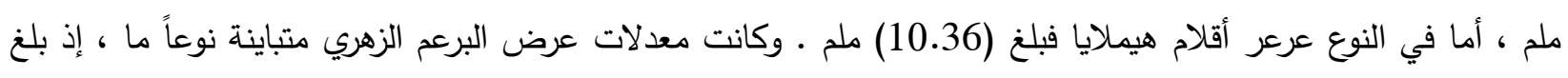
معدل عرض البرعم الزهري للإنواع الثلاثة المدروسة ( 3.93 ، 5.08 ، 4.26 ) ملم على التوالي ـ وكان الحامل الزهري قصير 


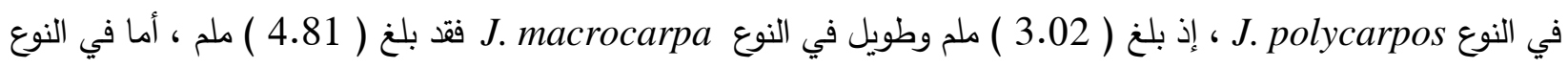
J. oxycedrus

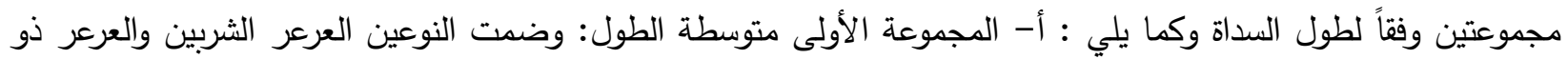
الثمار الكبيرة ، إذ بلغ معدل طول الاسدية لهما ( 2.53 و 3.88 ) ملم على التوالي • ب- المجموعة الثانية قصيرة الطول : وضمت النوع . polycarpos ، إذ بلغ معدل طول اسديته ( 1.45 ) ملم . وقد اتفتت هذه النتيجة مع نتيجة دراسة Daneshvar [ 17 ] ؛ ومع ؛Adams [22] الذين درسوا النوع العرعر بولي كاربوس في ايران وقد أكدوا على أن هذا النوع من العرعر ( J polycarpos ) هو وحيد المسكن monoecious. ولم تتفق هذه النتيجة مع نتيجة Djavanshir [24] الذي بين ان هذا النوع من العرعر ( عرعر أقلام هيملايا ) كان ثنائي المسكن ، تبين من خلال دراسة الأعضاء التكاثرية ( الجنسية )لأنواع العرعر في الدراسة الحالية أنها ذات أهمية في عزل وتثخيص ألأنواع قيد الدراسة، لما أمتازت به من ثبوتية ملحوظة لعدم تأثرها بالظروف البيئية المحيطة بالنبات، بل أنها تقع تحت تأثير وراثي. أما دراسة البذور

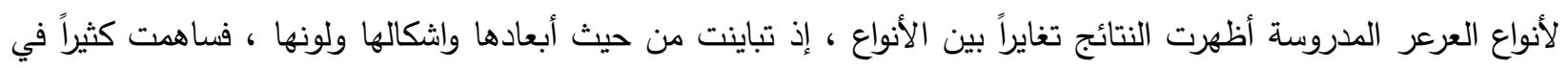

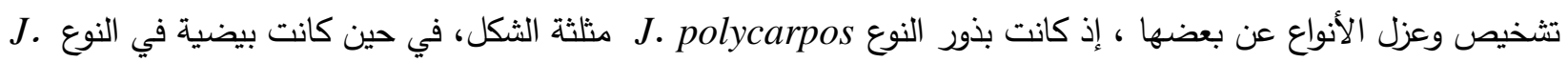
oxycedrus وبيضية - إهليلجية الثكل في النوع J . macrocarpa . فضلاً عن صفات لون وابعاد البذور كما مر بنا آنفا. الجدول ( 13 ) الصفات الكمية للبراعم الزهرية لانواع جنس العرعر قيد الدراسه مقاسة بالملمتر

\begin{tabular}{|c|c|c|c|c|c|c|c|c|}
\hline الكأس & طول الاسدية & داخل الزهرة & البتلات & طول الزهري الحامل & عرض البرهم & طول البرعم الزهري & الأنواع & $ت$ \\
\hline 3 & $\begin{array}{c}2.90-2.20 \\
(2.62)\end{array}$ & 3 & 3 & $\begin{array}{c}4.69-2.15 \\
(3.43)\end{array}$ & $\begin{array}{c}4.44-2.24 \\
(3.53)\end{array}$ & $\begin{array}{c}15.22-12.12 \\
(13.76)\end{array}$ & $\begin{array}{c}\text { J. oxycedrus } \\
1 \varepsilon\end{array}$ & 1 \\
\hline 3 & $\begin{array}{c}2.80-2.25 \\
(2.56)\end{array}$ & 3 & 3 & $\begin{array}{c}4.40-2.11 \\
(3.33)\end{array}$ & $\begin{array}{c}4.44-3.66 \\
(4.02)\end{array}$ & $\begin{array}{c}14.70-12.74 \\
(13.66)\end{array}$ & $\begin{array}{c}\text { J. oxycedrus } \\
2 \varepsilon\end{array}$ & 2 \\
\hline 3 & $\begin{array}{c}2.94-2.21 \\
(2.64)\end{array}$ & 3 & 3 & $\begin{array}{c}4.45-2.81 \\
(3.70)\end{array}$ & $\begin{array}{c}4.50-3.10 \\
(4.05)\end{array}$ & $\begin{array}{c}15.11-12.59 \\
(13.91)\end{array}$ & $\begin{array}{c}\text { J. oxycedrus } \\
j\end{array}$ & 3 \\
\hline 3 & $\begin{array}{c}2.99-2.25 \\
(2.54)\end{array}$ & 3 & 3 & $\begin{array}{c}3.82-1.50 \\
(2.67)\end{array}$ & $\begin{array}{c}4.65-3.50 \\
(4.06)\end{array}$ & $\begin{array}{c}15.38-11.56 \\
(13.17)\end{array}$ & $\begin{array}{c}\text { J. oxycedrus } \\
\omega\end{array}$ & 4 \\
\hline 3 & $\begin{array}{c}2.88-2.16 \\
(2.49)\end{array}$ & 3 & 3 & $\begin{array}{c}4.24-2.42 \\
(3.44)\end{array}$ & $\begin{array}{c}4.73-3.36 \\
(3.99)\end{array}$ & $\begin{array}{c}15.32-12.24 \\
(14.07)\end{array}$ & $\begin{array}{c}\text { J. oxycedrus } \\
\text { اتروش }\end{array}$ & 5 \\
\hline (3) & $(2.57)$ & (3) & (3) & (3.31) & (3.93) & $(13.71)$ & المعدل & \\
\hline 3 & $\begin{array}{c}4.66-3.25 \\
\quad(3.82)\end{array}$ & 3 & 3 & $\begin{array}{l}5.87-3.18 \\
\quad(4.78)\end{array}$ & $\begin{array}{l}5.80-4.15 \\
\quad(5.04)\end{array}$ & $\begin{array}{c}16.44-14.22 \\
(15.67)\end{array}$ & $\begin{array}{c}J . \\
\text { macrocarpa } \\
3 \varepsilon \\
\end{array}$ & 6 \\
\hline 3 & $\begin{array}{c}4.11-3.26 \\
(4.21)\end{array}$ & 3 & 3 & $\begin{array}{l}4.87-4.16 \\
\quad(4.63)\end{array}$ & $\begin{array}{c}4.97-4.16 \\
\quad(4.98)\end{array}$ & $\begin{array}{c}15.46-14.56 \\
(14.98)\end{array}$ & $\begin{array}{c}J . \\
\text { macrocarpa } \\
\text { تتروش }\end{array}$ & 7 \\
\hline (3) & $(4.01)$ & (3) & (3) & $(4.70)$ & $(5.01)$ & $(15.32)$ & المعدل & \\
\hline 3 & $\begin{array}{c}1.88-1.22 \\
(1.45)\end{array}$ & 3 & 3 & $\begin{array}{c}3.84-2.12 \\
(3.01)\end{array}$ & $\begin{array}{c}3.82-2.16 \\
(2.65)\end{array}$ & $\begin{array}{c}12.22-9.22 \\
(10.58)\end{array}$ & $\begin{array}{c}\text { J. polycarpos } \\
1 \text { قرشا }\end{array}$ & 8 \\
\hline 3 & $\begin{array}{c}2.01-1.16 \\
(1.57)\end{array}$ & 3 & 3 & $\begin{array}{c}3.56-2.20 \\
(3.05)\end{array}$ & $\begin{array}{c}5.86-4.87 \\
(5.15)\end{array}$ & $\begin{array}{c}11.12-9.23 \\
(10.26)\end{array}$ & $\begin{array}{c}\text { J. polycarpos } \\
2 ق ر ش\end{array}$ & 9 \\
\hline 3 & $\begin{array}{c}1.66-1.30 \\
(1.34)\end{array}$ & 3 & 3 & $\begin{array}{c}3.52-2.20 \\
(3.02)\end{array}$ & $\begin{array}{c}5.82-4.13 \\
(4.99)\end{array}$ & $\begin{array}{c}11.15-9.63 \\
(10.26)\end{array}$ & $\begin{array}{c}\text { J. polycarpos } \\
30 \text { قر }\end{array}$ & 10 \\
\hline (3) & $(1.45)$ & (3) & (3) & (3.02) & $(4.26)$ & $(10.36)$ & المعدل & \\
\hline
\end{tabular}




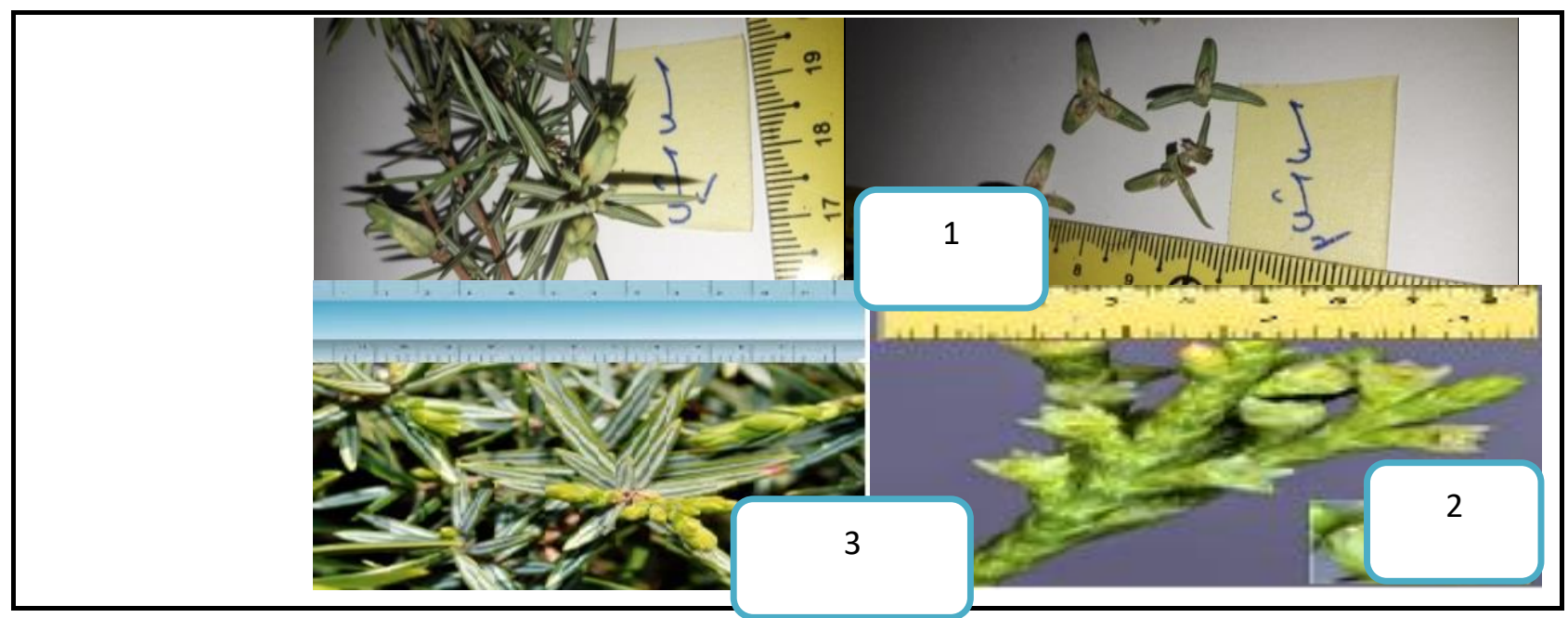

الثكل ( 8 ) التغاير في الصفات المظهرية للمخاريط الانثوية لإنواع العرعر المدروسة : J oxycedrus -1 . J. polycarpos - 3 J. macrocarpa

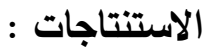

تسجيل نوع جديد في الموسوعة النباتية العراقية( الفلورا العراقية ) هو النوع Juniperus macrocarpa ، وتعد هذه الدراسة من الدراسات المهمة في تصنيف وتثخيص أنواع جنس العرعر .Juniperus L النامية في العراق لما امتازت به من شمولية

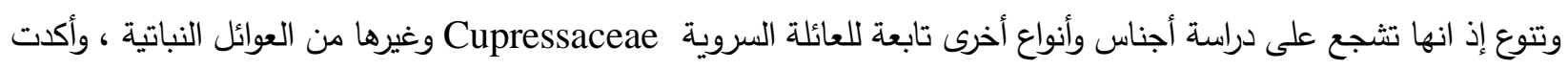

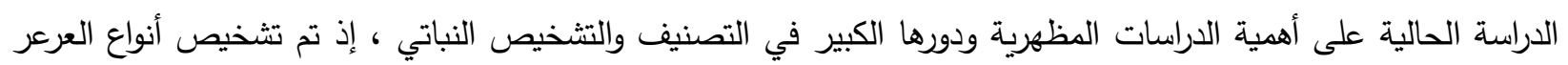
المدروسة باستخدام الصفات المظهرية كصفات الأوراق والثمار والبذور والقلف والمخاريط الذكرية والبراعم الزهرية. التي كان لها لهابها دور بارز في تشخيص وعزل الأنواع عن بعضها لما تمتلكه من تغايرات متعددة ساهمت بثكل فعال في عملية التشخيص. المصادر:

1- Ahani, H., Jalilvand, H., Hosseini-Nasr, S.M., Soltani, K.H., Ghazi, M.R. \& Mohammadzadeh, H. (2013). Iran. Forest Science and Practice 15, 231-237.

2- Olano, J.M., Rozas, V.; Bartolomé, D. and Sanz, D. (2008). Woodland. Forest Ecology and Management 255, 506-512.

3- Tylkowski, T. (2009).. Dendrobiology 61, 47-53.

4- Farjon, A. J. (2005). A Monograph of Cupressaceae and Sciadopitys. Royal Botanic Gardens Press: Kew.

5- Adams, R. P., Morris, J. A., Pandey, R. N., \& Schwarzbach, A. E. (2005).. Biochem. Syst. Ecol. 33:pp. 771-787. available online (pdf file) .

6- Daoud, Daoud Mahmoud (1979). Forest tree classification. Ministry of Higher Education and Scientific Research. Dar Al-Kotob for Printing and Publishing, College of Agriculture and Forestry, University of Mosul, Iraq.

7- Al-Musawi, A. H. I. (1987). Plant taxonomy, Dar Al-Kotob for printing and publishing, University of Mosul, Iraq.385pp.

8- Adams, R. P. (2004). Junipers of the World: The genus Juniperus. Trafford Publ., Vancouver, B. C. 426 pp.

9- Blue, M.P. and R. L. Jensen (1988 ). American Journal of Botany .75:pp. 939 - 947. 
10- Al-Jowary, H. S. J. (2017). PhD Dissertation, College of Agriculture and Forestry, University of Mosul, Iraq.

11- Al-Ani, B. O. A. and Qaisar N. S. (1988). Basics of plant anatomy. Baghdad University.

12- AL- Katib, Y. M. (2000). Classification of Seed Plants, Dar Al-Kutub for Printing and Publishing, university of Mosul, Iraq. 584pp.

13-Harlow, W. M. and E. S. Harrar, ( 1969). Textbook of Dendrology $5^{\text {th }}$ ed. McGraw- Hill co. New York: 512pp.

14- Nicolle, D. (2013). Native Eucalyptus of south Australia, Seedling paintings by Ian Roberts.

15-Klimko, M., Boratynska, K., Boratynski, A., and Marcysiak, K. (2004). Acta Societatis Botanicorum Poloniae. Vol. 73, No. 2:pp. 113-119. 2004.

16- Adams, R. P. ( 2010). Taxonomy Of Juniperus oxycedrus var. spilinanus in TURKEY.

17- Daneshvar, A. ( 2015 ). Doctoral Dissertation, Swedish University of Agricultural Sciences. Alnarp 2015.

18- Mao K., Hao G., Liu J., Adams, R. P. and Milne R. I.( 2010) New Phytologist 188(1): pp.254272.

19- Al-Jowary, H. S. J. (2009). Master Thesis, College of Agriculture and Forestry, University of Mosul, Iraq.

20- Al-Jowary, H. S. J., Younis M. Q., and Abdul Razzaq R. S. (2018). Al-Rafidian Agriculture Journal, Volume (46) No. (3). pp. 115-140.

21- Małgorzata M., Monika Z., Krystyna B., Angel R., Montserrat S. C., Katarzyna M. ( 2018). Journal Systematics and Biodiversity Volume 16, 2018 - Issue 5. pp. 469-482.

22- Adams, R. P. (2014). The junipers of the world: The genus Juniperus. 4th ed. Trafford Publ., Victoria, BC.

23- Pirani, A., Moazzeni, H., Mirinejad, S., Naghibi, F. \& Mosaddegh, M. (2104) . Ethnobotany Research \& Applications 9, pp.335-343.

24- Djavanshir, K. (1989). Silvae Genetica 23, 106-108. 